\title{
$\angle$ Research Square

\section{Molecular Mechanism of Engineered Zymomonas Mobilis Response to Furfural and Acetic acid Stress}

Samina Shabbir

Biogas Institute of Ministry of Agriculture

Weiting Wang

Biogas Institute of Ministry of Agriculture

Mao Chen

Biogas Institute of Ministry of Agriculture

Bo Wu

Biogas Institute of Ministry of Agriculture

Mohsin Nawaz

Hainan University

Panting Liu

Biogas Institute of Ministry of Agriculture

Yonghua Dai

Biogas Institute of Ministry of Agriculture

Lingling Sun

Biogas Institute of Ministry of Agriculture

Qiyu Gou

Biogas Institute of Ministry of Agriculture

Renbin Liu

Chengdu University of Science and Technology

Guoquan Hu

Biogas Institute of Ministry of Agriculture

Mingxiong He ( $\square$ hemxion@hotmail.com )

Biogas Institute of Ministry of Agriculture https://orcid.org/0000-0002-9780-6865

Research

Keywords: Acetic acid, Furfural, Zymomonas mobilis, Lignocellulosic biomass, RNA-Seq, Proteome

Posted Date: June 29th, 2021

DOI: https://doi.org/10.21203/rs.3.rs-629707/v1 
License: (c) (i) This work is licensed under a Creative Commons Attribution 4.0 International License. Read Full License 


\section{Abstract}

Backgroud: Acetic acid and furfural are two major inhibitors during lignocellulosic ethanol production. In our previous study, we successfully constructed an engineered Zymomonas mobilis ZM532 strain tolerant these double inhibitors by genome shuffling, but the molecular mechanisms of tolerance to these inhibitors are still unknown. This study investigated the responses of ZM532 and wild-type ZM4 to acetic acid and furfural using genomics, transcriptomics and label free quantitative proteomics.

Results: By Sanger sequencing technology we re-verified of previously identified 19 mutations in ZM532, but we found a total of 23 single nucleotide polymorphisms (SNPs) in the coding sequence (CDS; 4 ) and intergenic region (19) in ZM532. Six SNPs were novel in this study. We also identified a total of 1865 and 14 novel differentially expressed genes (DEGs) in ZM532 and wild-type ZM4. Among these, 352 DEGs were up-regulated; while and 393 were down-regulated in AF_ZM532 vs RM_532, respectively. However, 442 DEGs were up while 463 were down-regulated in AF_ZM4 vs RM_ZM4. Moreover, 2 up and 8 downregulated genes were identified in AF_ZM532 vs AF_ZM4; while 7 up and 1 down-regulated genes were found in RM_ZM532 vs RM_ZM. We also identified 1,532 proteins among 107 up and 204 downregulated proteins detected in ZM4_AF vs ZM4_RM, 123 up and 205 down regulated proteins were identified in ZM532_AF vs ZM532_RM, respectively. In addition, a total of 16 up and 5 down-regulated proteins were identified out of 1462 in ZM4_AF vs ZM532_AF, while 8 up and 5 down-regulated proteins were observed out of 1491 in ZM4_RM vs ZM532_RM. These proteins and genes are involved in amino acid biosynthesis, macromolecules repair, glycolysis, flagella assembly, ABC transporter, fermentation, and ATP synthesis pathways and stress response. These mentioned genes and proteins confirmed and help to unravel the acetic acid and furfural tolerance mechanism between ZM532 and wild-type ZM4. May be these proteins and genes play key roles in ZM532 regulation with strong expressions under acids stress conditions. Furthermore, we knocked-out and overexpressed two differentially expressed genes (DEGs), ZMO_RS02740 up-regulated and ZMO_RS06525 down-regulated to investigate their roles in acetic acid and furfural tolerance. Our knockout and complementary experiments revealed that upregulated expression gene ZMO_RS02740 and the down-regulated expression gene ZMO_RS06525 play important roles in dealing with furfural and acetic acid stress.

Conclusion: ZM532 can be used to substitute ZM4 as a biocatalyst for bioethanol under acetic acid and furfural condition, with a shorter fermentation time and higher productivity. Further studies may be required to clarify the relationship between the acid resistance and the genetic disparity of mutant strains.

\section{Background}

The rising global population and climate change have been decribed as major threats to life on earth. It is estimated that the world's population will reach 10 billion by 2030 [1]. Climate change is largely caused by human activities especially the burning of fossil fuels (coal, oil and gas) [2]. The desire for the world to curb human-induced climate change and ensure sustainable energy, and the call for environmentally friendly sources of energy has gained much attention in the last decade [3]. The alternative to fossil fuel 
is biofuel which is manufactured by microbial fermentation with failsafe renewable and sustainable energy sources that can mitigate climate change impacts and enhance energy security [4]. Due to its economic, social sustainability and environment advantages, lignocellulosic biomass biosynthesis into ethanol has received great attention. For fuel production, yeast strains are one of the main industrial biocatalysts for current generation [5]. Interestingly, engineered Escherichia coli, Zymomonas mobilis, and Bacillus subtilis have also successfully been deployed to meet the requirements of industrial biofuel catalysts [6].

Z. mobilis has gained prominence as an energy-generating bacterium of choice for higher ethanol yield or its special Entner Doudoroff (ED) pathway and attractive industrial potentials. For glucose metabolism, 1 mol of ATP is produced per molecule of glucose by using ED pathway [7]. However, during pretreatment, various inhibitors are naturally produced and hydrolysis processes such as furfural, vanillin, acetic acid, 5-hydroxymethyl furfural, aldehydes, phenols and other organic acids can significantly inhibit cell growth and efficiency of microbial fermentation $[8,9]$. Such inhibitors are detrimental to Z. mobilis growth and ethanol fermentation [10]. Acetic acid and furfural are major inhibitors that damage the stability of the membrane and intracellular homeostasis, resulting in lower $\mathrm{pH}$, osmotic stress, and reduced carbohydrate metabolism [11]. Due to lower production capacity and reduction in yields, the existence of these pretreatment inhibitors increases production costs. After pretreatment, these inhibitors can be extracted chemically or physically from the lignocellulosic biomass but these require extra tools which often increase cost of production.

Many genetic approaches, including forward and reverse genetics, have been applied to develop the inhibitor-resistant $Z$. mobilis strains [12-14]. Previously, a number of genes have also been cloned to study their involvement in ethanol production and related traits. Overexpression of the hfq (ZMO0347) encodes RNA chaperone and nhaA (ZMO0119) encodes sodium proton antiporter protein for enhanced ability of the mutant strain of $Z$. mobilis (ZM4)(AcR) to grow at a significantly higher concentrati on of sodium acetate $[15,16]$. In addition, [14] overexpression of three reductase genes (ZM01696, ZMO1116 and ZM01885) resulted in enhanced resistance to phenolic aldehyde inhibitors in ZM4 [14]. By multiround atmospheric and room temperature plasma (mARTP) mutagenesis, acid tolerant mutant strains developed recently has single nucleotide variants (SNVs) in glutamine-fructose-6-phosphate aminotransferase (ZMO0056) and DNA repair protein. RadA (ZMO0589) contributed to acid tolerance in mutant strains [17]. In corn stover hydrolysate, adaptive evolution and forward genetics were used to develop mutants that overcame inhibition caused by furfural, acetic acid and other inhibitors $[13,18,19]$. Through transcriptomic and proteomic profiling, Xu et al. [20] identified and overexpressed pntAB, fucO, ucpA and knocked out $y q h \mathrm{D}$ genes which induced furfural resistance in $E$. coli. Also, several studies have reported the role of key genes/transcriptional factors for improving furfural resistance [21-27].

Previously in our lab, we develped a resistant strain, F34, which is tolerant to $3.0 \mathrm{~g} / \mathrm{L}$ furfural, AQ8-1, and $8.0 \mathrm{~g} / \mathrm{L}$ acetic acid by mARTP mutagenesis in Z. mobilis [28]. Another strain, ZM532 mutant derived form genome shuffling, which is superior to the parental strain AQ8-1 in the presence of $7.0 \mathrm{~g} / \mathrm{L}$ acetic acid and $3.0 \mathrm{~g} / \mathrm{L}$ furfural, was of higher productivity $(0.463 \mathrm{~g} / \mathrm{L} / \mathrm{h})$ and shorter fermentation (30 hours) than AQ8-1 
[10]. But we haven't explored the global transcriptional profile difference between ZM532 mutant and wild-type ZM4 especially in the conditions of rich media (RM) and media containg acetic acid and furfural (AF) which is potentially important at industrail level. So, in this study, sanger sequencing firstly used to verified the mutations in ZM532, and then we applied transcriptomics and proteomics to unravel molecular mechanisms in the wild type (ZM4) and mutant strain (ZM532) under AF and RM conditions. By this we identified large number of genes and proteins which are resposible for tolerance against acids and they were also used to hypothesized for media, strain, treatment and growth conditions responsive. Further, we knocked-out and overexpressed two differentially expressed genes (DEGs), ZMO_RS02740 and ZMO_RS06525, to study their modulating roles in acetic acid and furfural (AF) condition. The results provided here deepen our understanding of ethanol production by genetic engineering and/or synthetic biology.

\section{Results And Discussion}

\section{ZM532 re-sequencing for confirmation of previously identified mutations}

The mutant, ZM532 was constructed by genome shuffling. The ZM532 exhibited superior performance with a shortened fermentation time (30 hours) and higher ethanol production $(0.463 \mathrm{~g} / \mathrm{L} / \mathrm{h})$ compared to the parental strain AQ8-1 in 7.0 g/L acetic acid medium [10]. We identified 23 single nucleotide polymorphisms (SNPs) in the coding sequence (4CDS and 19 within the intergenic region) via Sanger sequencing. Six SNPs were novel in this study (Table 1). Wang et al. [10] identified 19 identical SNPs in wild type ZM4 located in the CDS (6) and 13 in the intergenic regions, respectively (Table 1). 
Table 1

SNP in re-sequence ZM532 by comparing previous published ten genome

\begin{tabular}{|c|c|c|c|c|c|c|}
\hline Locus & $\begin{array}{l}\text { Ref } \\
\text { a }\end{array}$ & $\begin{array}{l}\text { Previous } \\
\text { b }\end{array}$ & $\begin{array}{l}\text { Current } \\
c\end{array}$ & Status & $\begin{array}{l}\text { Ten } \\
\text { genome } \\
\text { shuffled d }\end{array}$ & Gene/Product \\
\hline \multicolumn{7}{|l|}{ CDS } \\
\hline 51967 & C & $\mathrm{T}$ & $\mathrm{T}$ & Confirmed & + & $\begin{array}{l}\text { ZMO_RS00235/glutamine- } \\
\text { fructose-6-phosphate } \\
\text { aminotransferase }\end{array}$ \\
\hline 590452 & G & A & A & Confirmed & + & $\begin{array}{l}\text { ZMO_RS02620/DNA repair } \\
\text { protein Rad A }\end{array}$ \\
\hline 849208 & C & $\mathrm{T}$ & $\mathrm{T}$ & Confirmed & + & $\begin{array}{l}\text { ZMO_RS03765/arginine-tRNA } \\
\text { ligase }\end{array}$ \\
\hline 849311 & C & A & A & Confirmed & + & \\
\hline 971308 & A & G & - & $\begin{array}{l}\text { No SNP } \\
\text { found }\end{array}$ & - & $\begin{array}{l}\text { ZMO_RS09165/1S5/1S1182 } \\
\text { family transposase }\end{array}$ \\
\hline 971369 & A & G & - & $\begin{array}{l}\text { No SNP } \\
\text { found }\end{array}$ & - & \\
\hline \multicolumn{7}{|c|}{ Intergenic regions } \\
\hline 971059 & $\mathrm{~T}$ & $A$ & A & Confirmed & + & ZMO_RS09160-ZMO_RS09165 \\
\hline 971715 & C & - & $\mathrm{T}$ & New SNP & + & $?$ \\
\hline 971717 & $\mathrm{~T}$ & - & G & New SNP & + & \\
\hline 975503 & $\mathrm{~T}$ & G & G & Confirmed & + & ZMO_RS04290-ZMO_RS04295 \\
\hline 975506 & G & A & A & Confirmed & + & $\begin{array}{l}\text { Monofunctional biosynthetic } \\
\text { peptidoglycan }\end{array}$ \\
\hline 975509 & C & $\mathrm{T}$ & $\mathrm{T}$ & Confirmed & + & Transglycosylase/cytochrome c \\
\hline 975523 & C & $\mathrm{T}$ & $\mathrm{T}$ & Confirmed & + & \\
\hline 975525 & A & $\mathrm{T}$ & $\mathrm{T}$ & Confirmed & + & \\
\hline 975528 & $\mathrm{~T}$ & G & G & Confirmed & + & \\
\hline 975532 & A & $\mathrm{T}$ & $\mathrm{T}$ & Confirmed & + & \\
\hline 975537 & A & C & C & Confirmed & + & \\
\hline 975540 & G & $\mathrm{T}$ & $\mathrm{T}$ & Confirmed & + & \\
\hline
\end{tabular}

a Reference genome ZM4. ${ }^{\text {b }}$ Wang et al. [10]. ${ }^{c}$ Current study with ZM532 strain. ${ }^{d}+/$ - indicate the presence/absence of variation in the genome, respectively. 


\begin{tabular}{|c|c|c|c|c|c|c|}
\hline Locus & $\begin{array}{l}\text { Ref } \\
a\end{array}$ & $\begin{array}{l}\text { Previous } \\
\text { b }\end{array}$ & $\begin{array}{l}\text { Current } \\
\text { c }\end{array}$ & Status & $\begin{array}{l}\text { Ten } \\
\text { genome } \\
\text { shuffled }^{d}\end{array}$ & Gene/Product \\
\hline 975544 & A & - & $G$ & New SNP & + & \\
\hline 975545 & G & - & A & New SNP & + & \\
\hline 975547 & $\mathrm{~T}$ & G & G & Confirmed & + & \\
\hline 975899 & $\mathrm{~T}$ & & C & New SNP & + & ZMO_RS04295 \\
\hline 1612575 & G & A & - & $\begin{array}{l}\text { No SNP } \\
\text { found }\end{array}$ & - & ZMO_RS07065-ZMO_RS07070 \\
\hline 1612744 & G & - & A & New SNP & + & Alpha/betahydrolase/Trna-Met \\
\hline 2055763 & $\mathrm{~T}$ & C & C & Confirmed & + & ZMO_RS09095-END \\
\hline 2055333 & G & - & A & New SNP & + & $\begin{array}{l}\text { Uroporphyrinogen } \\
\text { decarboxylase/END }\end{array}$ \\
\hline
\end{tabular}

The four SNPs in the CDS regions caused variation in the amino acid (AA), resulting in synonymous and non-synonymous mutations (Table 1). In ZMO_RS03765 (arginine-tRNA ligase) one non-synonymous and synonymous AA change was observed at the same time. In contrast, in ZMO_RS00235 and ZMO_RS02620, two non-synonymous AA changes were observed, which were linked to glutaminefructose-6-phosphate aminotransferase and DNA repair protein RadA, respectively (Table 1). While the gene ZMO_RS02620 encodes a DNA repair protein called RadA, which is necessary for cellular survival when cells are exposed to acid stress [29]. Jeong et al. [30] reported that under acid stress in E. coli 0157: $\mathrm{H} 7$ strand disintegrates and DNA integrity was retained by Dps and RecA-mediated repairs, indicating that DNA repair can play an important role in acid tolerance. Wang et al. [10] identified two non-synonymous AA changes in ZMO_RS09165 (IS5/IS1128 family transposase) but these were absent in the present study. Conversely, we found SNPs in the intergenic regions of the pairs of genes: ZMO_RS09160 and ZMO_RS09165; ZMO_RS04290 and ZMO_RS04295; and ZMO_RS07065 and ZMO_RS07070 in ZM532 mutant. Conversely, ZMO_RS04290 and ZMO_RS04295 which encode monofunctional encoding MBPT and cytochrome $\mathrm{c}$ to promote glycan chain synthesis in bacterial cell walls and its function is identical to that of DNA polymerases [31]. This could be important to preserve the integrity and tolerance of the cells to the inhibitor. This is consistent with report by Wang et al. [10]. There was also a frameshift mutation in ZMO_RS04405, which codes for ABC transporter substrate-binding protein because of two single nucleotides deletion in the CDS region (Table S1). We also detected - 21 bp deletion in the ZMO_RS05590 (hypothetical protein) while the previous studies identified two distinct deletion (-21 bp and - $28 \mathrm{bp}$ ) in different locations of the same gene. Additionally, there was a -7 bp deletion in ZMO_RS07255 (carbamoyl phosphate synthase large subunit) and $-1 \mathrm{bp}$ InDel in the intergenic region of ZMO_RS06410-ZMO_RS06415 (Additional file 5: Table S5). ADI genes, as previously reported by Ryan et 
al. [32], allow Listeria monocytogenes to survive under acidic conditions, with arginine their expression is become higher at low $\mathrm{pH}$. In short, genes involved in the same mutations on the parental and mutant strains have been reported previously and may be play critical role against acids stressors.

\section{Overview of Transcriptome under inhibitors (AF)}

The RNA-seq yielded a total of $32.79 \mathrm{~Gb}$ clean data, averaging $2.73 \mathrm{~Gb}$ for each sample with $91 \%$ of bases recording Q30 and above, with a $q \geq 20$ (an error probability of $0.03 \%$ ) (Additional File 6: Table S6). The GC-contents in the four distinct groups ranged from 48.26-49.15. A gene was considered differentially expressed (DEG) after comparing the gene expression profiles between RM and AF treatments with fold change $(\mathrm{FC})>1.5$ and FDR corrected $p<0.05$. A total of 1865 and 14 novel DEGs were identified by using the genome of parental strain ZM4 (ATCC 31821) as the Ref. [33].

\section{Differentially expressed genes in ZM532 and ZM4 and their expression profiles}

In total, we identified 745 and 905 DEGs in ZM532 and ZM4, respectively (Fig. 1A, B, Additional File 7: Table S7, Additional File 8: Table S8). Among these, 352 DEGs were up-regulated; while and 393 were down-regulated in AF_ZM532 vs RM_532, respectively. However, 442 DEGs were up-regulated while 463 were down-regulated in AF_ZM4 vs RM_ZM4 (Fig. 1A-B). In addition, only 2 up and 8 down-regulated genes in AF_ZM532 vs AF_ZM4; while 7 up and 1 down-regulated genes in RM_ZM532 vs RM_ZM (Fig. 1C-D). The higher number of DEGs detected in the strain ZM4 suggests intense transcriptional alteration in response to the inhibitors due to ZM4 relative sensitivity. We performed hierarchical cluster analysis based on the $\log _{2}$ FC and FPKM values to validate the DEGs from ZM4 and ZM532 strains (Figure S1). The analysis clustered the DEGs into two main groups with the two strains clustering together regardless of the treatments. This implies that very few DEGs were distinguishable between these two strains in their response to AF treatments.

\section{Gene ontology enrichment analysis}

We further performed GO enrichment analysis on the DEGs to identify enriched GO terms among the upand down-regulated genes in the two samples in the response to the inhibitors. GO terminologies with adjusted $p<0.05$ were significantly enriched. The DEGs in both ZM532 and ZM4 had relatively similar GO terms; however, organonitrogen compound biosynthesis (GO:1901566, 120 DEGs)", cellular amide metabolic process (GO:0043603, 78 DEGs)", amide biosynthetic process (G0:0043604, 76 DEGs)", translation (G0:0006412, 68 DEGs), peptide biosynthesis process (GO: 0043043, 68 DEGs), peptide metabolic process (GO: 0006518, 69 DEGs), cellular process (GO: 0009987, 337 DEGs), and cellular macromolecules biosynthesis (G0: 0034645, 132 DEGs) were the dominant biological processes in AF_ZM532vsRM_532 (Fig. 2A). In the AF_ZM532 vs RM_532, 16 GO terms were significantly enriched in the "biological process" and "molecular function" categories (Fig. 2A; Additional File 9: Table S9A-B). Similarly, in AF_ZM4 vs RM_ZM4, the genes were mostly involved in biological process such as translation (GO: 0006412, 67 DEGs), peptide biosynthetic process (GO: 0043043, 67 DEGs) and peptide metabolic process (GO: 0006518, 69 DEGs) (Fig. 2A). The molecular functions recorded "structural 
molecule activity (GO: 0005198" in both AF_ZM532 vs RM_532 and AF_ZM4 vs RM_ZM4 as the most enriched terms. In the AF_ZM4 vs RM_ZM4 strain, 14 GO terms were significantly enriched in the "biological process" and "molecular function" categories (Fig. 2B). Interestingly, ribosomes biogenesis (GO: 0042254) and translation (GO: 0006412) which are associated with protein synthesis were the most significantly enriched GO terms. These results indicate synthesis of protein in bacteria are markedly altered with modification of culture conditions. Interestingly, we found DEGs involved in high oxidoreductase activity were up-regulated in AF_ZM532 vs RM_532 but down-regulated in AF_ZM4 vs RM_ZM4 (Fig. 2A-B; Additional File 9: Table S9A-B). In addition, organonitrogen compound biosynthesis (GO: 1901566, 4), cellular amide metabolic process (GO: 0043603, 3 DEGs), cellular protein metabolic process (GO: 0043603, 3 DEGs) and gene expression (GO: 0010467, 4 DEGs) were most enriched Go biological terms in AF_ZM532 vs AF_ZM4 (Fig. 2C), while structural molecular activity (GO: 0005198, 3 DEGs) was most enriched molecular function term. But in case of RM_ZM532 vs RM_ZM (Fig. 2D), transport (GO: 0006810, 4 DEGs), establisment of localization (GO: 0051234, 4 DEGs) and localiztion (GO: 0051179, 4 DEGs) were Go enriched biological terms, while oxidoreductase activity (GO: 0016491, 1 DEGs) and hydrolase activity (GO: 0016787, 1 DEGs) were enriched GO molecular function terms.

Subsequently, we searched for candidate genes involved in the tolerance mechanism against the inhibitors by comparing the DEGs between the two strains. We detected 98 DEGs were exclusively involved in the AF resistance in ZM532, including 42 up-regulated DEGs in response to the inhibitors and associated with oxido-reductase activity (Figure S2A). Additional 647 DEGs were mutually detected in both samples. While in AF_ZM532 vs AF_ZM4 (purple) and RM_ZM532 vs RM_ZM4, only 1 DEGs was codetected in both strain. We identified 7 DEGs to RM_ZM532 vs RM_ZM4 and 9 to AF_ZM532 vs AF_ZM4

(Figure S2B). The most up- and down-regulated DEGs were ZMO_RS02740 ( $\left.\log _{2} F C=6.05\right)$ and ZMO_RS06525 ( $\log _{2}$ FC $=-2.373$ ) in the ZM532 strain. These candidate DEGs represent important resources for further functional validation in AF resistance in Z. mobilis.

\section{Label free data and functional annotation of the proteins}

To elucidate the molecular response, tolerance to acetic acid and furfural inhibitors, the proteomes of the two Z. mobilis strains (ZM4 and its mutant ZM532) were generated under control and treatment conditions. We successfully identified a total of 1532 proteins in both samples (Table 2). The mutant strain ZM532 was more resistant to the inhibitors as compared to ZM4 (Table 2). The number of proteins detected in the AF samples were lower than in the RM samples (Figure S3A), suggesting that proteins synthesis in Z. mobilis was inhibited by the treatment. Mass distribution and protein length of most of the identified proteins were between 10-60 kDa and 6-20 amino acids, respectively (Figure S3B, C). There was less variability in the majority of the detected proteins $(C V<0.2)$ (Figure S3D). The proteins were functionally annotated by BLASTP (E value $\leq 1 \mathrm{e}-4$ ) using the COG, GO, KEGG and IPR databases (Table S10). We successfully annotated $99 \%$ of the total proteins in at least one database (Addition File10: Table S10: Fig. 3A) and 976 proteins (76\%) were annotated in all the four databases. The function of protein is usually associated with its subcellular localization, the capability to predict subcellular localization directly from protein sequences is beneficial to inferred protein functions. The statistical 
analysis of the proportion of subcellular location (Cell-mPLOC 2.0 website) of the differential protein is shown in Figure S4. The identified proteins demonstrated that $52.17 \%$ proteins were found in resemblance with cytoplasmic proteins; $32.61 \%$ proteins significant hits for cell inner membrane proteins, followed by periplasm proteins $(5.34 \%)$, extracellular proteins $(2.57 \%)$, flagellum proteins $(0.59 \%)$ and $0.20 \%$ proteins with nucleoid protein. Furthermore, PCA was performed based on the protein expression profile (Addition File10: Table S10). More than half of the total variations were accounted for by the first two PCs, indicating that AF treatment significantly altered the proteome in both strains (Fig. 3B).

Table 2

Statistics on the label free data

\begin{tabular}{|llll|}
\hline Total spectra & Matched spectrum & Peptides & Identified proteins \\
\hline 1647059 & 364149 & 23673 & 1532 \\
\hline
\end{tabular}
Differentially expressed proteins in response to the
inhibitors (AF)

The protein expression data was compared between control and treatment groups to detect the differentially expressed proteins (DEP) based on the fold change $>1.5$ and $p<0.05$. A total of 107 up and /204 down-regulated proteins out of 1477 were detected in ZM4_AF vs ZM4_RM; while and 123 upregulated and 205 down-regulated proteins of 1474 were identified in ZM532_AF vs ZM532_RM, respectively (Addition File11: Table S11; Addition File12:Table S12: Fig. 3C-D). In addition, a total of 16 up and 5 down-regulated proteins were identified out of 1462 in ZM4_AF vs ZM532_AF, while 8 up and 5 down-regulated proteins were observed out of 1491 in ZM4_RM vs ZM532_RM (Fig. 3E-F). Comparative analysis of the DEPs between ZM4 and ZM532 revealed 186 DEPs shared the same pattern of regulation (Addition File13: Table S13: Figure S5). This suggests they represent the core proteome response to the inhibitors, regardless of the tolerance level of the Z. mobilis strains.

\section{Pathway enrichment analysis of the differentially expressed proteins}

GO and KEGG enrichment analyses were performed to understand the biological pathways activated in response to the inhibitors (Fig. 4A-B). For GO enrichment analysis, we mainly focused on molecular function and cellular component classes. In the two strains, DEPs related to 'non-membrane-bounded organelle', 'large ribosomal subunit', and 'ribosome' were the enriched terms in the GO cellular component class, indicating major alterations in the ribosome were induced by the inhibitors. These proteins mainly contributed to 'structural molecule activity', 'electron carrier activity' and 'structural constituent of ribosome' (molecular function terms) which denotes that the inhibitors affect the structural integrity and normal ribosome activity. While in ZM4_AF vs ZM532_AF, DEPs maily related to hydrolase activity, edonuclease activity and damage DNA binding were more enrished molecular functions terms. Moreover, hydrolases activity are important against inhibitors, which involved in several critical functions such as maturation, turnover, recycling, and autolysis. In addition, DNA damage binding activity has a direct 
relationship to decreased nucleotide excision repair and Endonucleases play a role in DNA repair in resistance strain ZM532 (Fig. 4C). But in case of ZM4_RM vs ZM532_RM, most of DEPs linked with plasma membrane at cellular level, while at molecular level DEPs were invloved in $\mathrm{N}$-acetyletransferase activity (Fig. 4D).

A similar result obtained concerning the KEGG enrichment analysis in the two strains, highlighting 'ribosome' as the most affected pathway (Fig. 5A-B). In addition, flagellar assembly, peptidoglycan biosynthesis and ribosome were enriched KEEG pathways in ZM4_AF vs ZM532_AF while folate biosynthesis, amino sugar and nucleotide sugar metabolism and $A B C$ transporter were most enriched term in ZM4_RM vs ZM532_RM (Fig. 5C-D).

The identified DE proteins were mapped to the reference pathways in the KEGG database, and 21 different biological pathways were obtained in 4 major categories (Fig. 5E). The KEGG pathways (which include 914 proteins) were members of a major group, metabolism, 153 linked to genetic information processing, 59 related to cellular processes, and 87 related to environmental information (Figure S6). KEGG enrichment analysis in the two strains also affirms 'ribosome' as the most affected pathway in both strains. Analysis of expression fold changes of the proteins involved in selected pathways revealed that the resistant strain (ZM532) strongly delayed the activity in the ribosome by reducing the synthesis of all ribosome-assembly proteins under AF treatment (Table 3), a mechanism known as hypometabolism [34]. In contrast, several ribosome-assembly proteins were either up-regulated or unaffected following AF treatment in ZM4 (Table 3). We speculate that the ability to limit ribosome activity is an effective adaptation mechanism against AF.

Table $3 \mathrm{Log}_{2}$ fold change expression of the proteins involved in ribosome assembly and functioning under inhibitor (AF) as compared to control (RM) treatment. Blue and red cells are up-regulated and downregulated proteins, respectively $(p<0.05)$. 


\begin{tabular}{|c|c|c|c|c|c|}
\hline Locus position & Gene & Proteins & Description & ZM4_AF v $\mathrm{RM}$ & ZM532_AF vs RM \\
\hline ZMO_RS09205 & rpmF & WP_011241625.1 & 50 S ribosomal protein L.32 & -1.693376596 & -2.963701617 \\
\hline ZMO_RS00905 & rpmA & WP_011240160.1 & 50 S ribosomal protein $\mathrm{L} 27$ & -2.239294866 & -2.82663374 \\
\hline ZMO_RS02700 & & WV_011240508.1 & $\begin{array}{l}\text { flagellar basal body P-ring } \\
\text { protein }\end{array}$ & -2.075099131 & -2.442245564 \\
\hline ZMO_RS01075 & rpmG & WP_011240192.1 & 50 S ribosomal protein L 33 & -1.413276531 & -1.796967056 \\
\hline ZMO_RS05740 & & WP_011241086.1 & c-type cytochrome & -1.670112359 & -0.5 \\
\hline ZMO_RS08135 & $\mathrm{rsxG}$ & WP_011241543.1 & $\begin{array}{l}\text { electron transport complex } \\
\text { subunit }\end{array}$ & -1.472394467 & -0.961994725 \\
\hline ZMO_RS02375 & $\mathrm{rpsK}$ & WP_011240446.1 & 30 S ribosomal protein $\$ 11$ & -1.468868244 & -1.497153953 \\
\hline $\begin{array}{l}\text { ZMO_RS03950 } \\
\text { ZMO_RS08150 }\end{array}$ & $\mathrm{rplM}$ & WP 011240748.1 & $\begin{array}{l}50 \text { ribosomal protein } \mathrm{L} 13 \\
\text { Rnf electron transport }\end{array}$ & -1.46081465 & -1.638822223 \\
\hline & & WP 011241546.1 & subunit B & -1.325746722 & -1.672912675 \\
\hline ZMO_RS02280 & $\mathrm{rpsS}$ & WP 011240427.1 & 30 S ribosomal protein $\$ 19$ & -1.185949111 & -1.450193214 \\
\hline ZMO_RS05125 & $\mathrm{rpmE}$ & WP_011240972.1 & 50 S ribosomal protein L 31 & -1.006448642 & -1.113315192 \\
\hline ZMO_RS02830 & & WP_011240533.1 & hypothetical protein & -0.984323428 & 0 \\
\hline ZMO_RS02315 & $\mathrm{rplX}$ & WP_011240434.1 & 50 S ribosomal protein L 24 & -0.974994731 & -0.5 \\
\hline ZMO_RS05080 & & WP_011240963.1 & c-type cytochrome & -0.912399263 & -0.657372039 \\
\hline ZMO_RS02340 & $\mathrm{rplR}$ & WP_011240439.1 & 50 S ribosomal protein L18 & -0.869150003 & -0.967603431 \\
\hline ZMO_RS02285 & $\mathrm{rplV}$ & WP_011240428.1 & 50 S ribosomal protein L 22 & -0.849931082 & -0.814477807 \\
\hline ZMO_RS02845 & & WP 011240536.1 & flagellar basal body-associated & -0.822055549 & 0 \\
\hline ZMO_RS02305 & $\mathrm{rp}: \mathrm{Q}$ & WP_011240432.1 & 30 S ribosomal protein S17 & -0.762656879 & -0.798262818 \\
\hline ZMO_RS09190 & $\mathrm{rpmH}$ & WP_080502949.1 & 50 S ribosomal protein L34 & -0.736130953 & -2.102742998 \\
\hline ZMO_RS06110 & $\mathrm{rpsD}$ & WP_011241155.1 & 30 S ribosomal protein $\$ 4$ & -0.691968526 & -0.5 \\
\hline ZMO_RS02685 & & WP_011240505.1 & flagellin & 0.598050654 & 1.086024016 \\
\hline ZMO_RS02325 & $\mathrm{rpaN}$ & WP_011240436.1 & 30 S ribosomal protein S14 & 0.758387159 & -0.5 \\
\hline ZMO_RS06800 & $\mathrm{rplT}$ & WP_011241288.1 & 50 S ribosomal protein L 20 & 0.90504518 & -0.5 \\
\hline ZMO_RS04295 & & WP_011240814.1 & cytochrome c & 1.077083442 & 0.80380681 \\
\hline ZMO_RS08485 & & WP_011241601.1 & $\begin{array}{l}\text { Grx4 family monothiol } \\
\text { glutaredoxin }\end{array}$ & 1.092696396 & 0.745006138 \\
\hline ZMO_RS00940 & & WP_011240167.1 & ferredoxin family protein & 1.120677338 & 1.611927861 \\
\hline ZMO_RS03370 & $\mathrm{gxC}$ & WP 011240634.1 & glutaredoxin 3 & 1.550053095 & 1.599730579 \\
\hline ZMO_RS05510 & $\mathrm{rps}$ & WP_011241043.1 & 30 S ribosomal protein S18 & 1.728082102 & -0.3 \\
\hline ZMO_RS09185 & $\mathrm{rpmI}$ & WP_011241289.1 & 50 S ribosomal protein L 35 & 2.480562838 & -0.3 \\
\hline ZMO_RS02235 & rpaL & WP_011240418.1 & 30 S ribosomal protein $\mathrm{S} 12$ & 0 & -1.96626993 \\
\hline ZMO_RS01270 & $\mathrm{rpmB}$ & WP_011240230.1 & 50 S ribosomal protein L28 & 0 & -1.538518884 \\
\hline ZMO_RS07710 & $\mathrm{rpaU}$ & WP_011241460.1 & 30 S ribosomal protein $\$ 21$ & 0 & -1.268835417 \\
\hline ZMO_RS00910 & rplu & WP_014500625.1 & $50 S$ ribosomal protein L21 & 0 & -1.009644328 \\
\hline ZMO_RS03945 & rpaI & WP 011240747.1 & 30 S ribosomal protein S9 & 0 & -0.953261652 \\
\hline ZMO_RS02355 & & WP_011240442.1 & 50 S ribosomal protein L15 & 0 & -0.894001947 \\
\hline ZMO_RS02240 & $\mathrm{rpgG}$ & WP_011240419.1 & 30 S ribosomal protein $\$ 7$ & 0 & -0.797966221 \\
\hline ZMO_RS02335 & $\mathrm{rplF}$ & WP_011240438.1 & 50S ribosomal protein L6 & 0 & -0.770759431 \\
\hline ZMO_RS02265 & $\mathrm{rplD}$ & WP_011240424.1 & 50 S ribosomal protein $\mathrm{L} 4$ & 0 & -0.694990945 \\
\hline ZMO_RSO2350 & $\mathrm{rpmD}$ & WP 011240441.1 & 50 S ribogomal protein L 30 & 0 & -0.689036623 \\
\hline
\end{tabular}

\section{Genome, Gene and Protein Correlations}

Integrative molecular approaches such as genome, transcriptome and proteome may help us to gain a deep understanding of toxicants' effects at multiple levels of biological organization, while also facilitating in risk assessment. We identified two key mutations ZMO_RS00235 and ZMO_RS03765 in our transcriptome data, which encode glutamine-fructose-6-phosphate aminotransferase and arginine-tRNA ligase (Fig. 6A) as described earlier and our current sanger re-sequencing data [10]. The gene, ZMO_RS00235 was up-regulated in the mutant strain which may contribute to furfural and acetic acid stress tolerance. ZMO_RS00235 was previously reported to be critical for organic acid stress in cells [10, 29]. Moreover, ZMO_RS03765 is associated with arginine biosynthesis which is crucial for acid stress. However, no concrete evidence has been adduced for the role of arginine in acid resistance, the cell wall/membrane itself may be important to maintain cell integrity. 
In addition, we also identified two important mutations such as ZMO_RS06410 and ZMO_RS04295 in the proteome data (Additional file 14: Table S14) as reported previously [10] and current re-sequencing data. ZMO_RS06410 might improve fusidic acid resistance and methicillin-resistance, it may also be useful for Z. mobilis to survive acid stress [35,36]. One of the genes, ZMO RS04295 encoding MBPT and cytochrome $\mathrm{c}$ to promote glycan chain synthesis in bacterial cell walls and its function is identical to that of DNA polymerases [31]. This could be important to preserve the integrity and tolerance of the cells to the inhibitors. These mutations have roles in acids tolerance as cytochrome $\mathrm{C}$ may provide some protective layer sheet against acetic acid and furfural stresses.

To identify some corresponding relationships, the transcriptome data was combined with the proteome data. A total of 662, 578, 1379 IDs were identified in ZM532_AF vs ZM532_RM, AF_532 vs RM_532, ZM4_AF vs ZM4_RM, AF_ZM4 vs RM_ZM4 and ZM532_AF vs ZM4_AF, AF_532 vs AF_ZM4 by both RNAseq and proteomics (Figure S7A-C). In the three groups, 111, 138 and 1 unique proteins related to transcriptome DEGs, were identified, respectively. Correlation analysis was performed between the multiples of genes (proteins) reported by transcriptome and proteome study in the three groups (Figure S7A-C). Among mRNA and the corresponding protein, the Pearson correlation coefficient was positive (Pearson $=0.233,0.217$ and 0.014) for all groups, respectively (Figure S7D-F). As a result, we suggest that it is critical to assess protein expression in order to understand phenotypic changes and not relying solely on transcriptional level.

\section{Candidate genes and proteins involved in motility of cell, membrane components and envelope biogenesis contributed in stability of cell membrane}

Several DEPs were associated with membrane, cell wall, cell motility and envelope biogenesis in the presence of acetic and furfural acids. Proteins associated with membrane and membrane components were up-regulated with enhanced tolerance to acidic acid and furfural. In bacteria, presence of TonBdependent transporters are necessary for active absorption of complexes such as carbohydrates and iron $[37,38]$ as iron assimilation is crucial in some bacteria. TonB-dependent transport proteins may contribute to resistance to osmotic pressure [39]. Here, our proteomics results revealed that TonB transporter proteins; ZMO_RS07620, ZMO_RS06825, ZMO_RS07005 and ZMO_RS06600 were downregulated in the resistant strain ZM532. Contrary, a down-regulated gene ZMO_RS00805 encoded TonBdependent siderophore receptor in ZM4 (Additional file 14: Table S14). Nonetheless, our transcriptomics results revealed TonB-dependent transporter genes (ZMO_RS00540, ZMO_RS04385, ZMO_RS07620 and ZMO_RS07730) were down-regulated in the mutants, ZM532 and ZM4 (Additional file 7, 8: Table S7, S8). The down-regulation of TonB-dependent transporter proteins are consistent with results by [40]. ZM532 (mutant strain) recorded more down-regulated proteins compared to ZM4. This may be ascribed to the down-regulation of the TonB-dependent transporters resulting in decreased energy for the absorption of substrates and reserve energy for stressors.

Acetic acid substrates are transported by $A B C$ transporters as acetic acid tolerance mechanism [40]. The transcriptomics results demonstrated that genes encoding ABC transporters such as ZMO_RS08315, 
ZMO_RS04690,ZMO_RS01550, ZMO_RS02545 and ZMO_RS01130 were significantly up-regulated in ZM532 (Additional file 7, 8: Table S7, S8). The up-regulation of ABC transporter genes were consistent with results from acidic-pH treatment [41, 42]. The up-regulation of $A B C$ transporters may enhance and sustain the cytoplasmic pH homeostasis in mutant strain ZM532 under AF conditions. Additionally, RND efflux pump is essential for supply of different metabolites with the proton antiport (including antibiotics, and basic organic solvents). This is effective for detoxifying external toxic compounds and internal harmful intermediates [43]. RND efflux pump was encoded by ZMO_RS03470 in the proteome while ZMO_RS03475, and ZMO_RS06835 were significantly down-regulated under acidic condition in both ZM4 and ZM532 (Additional file 7, 8: Table S7, S8; Additional file 14: Table S14). This is in consonance with report by Wu et al. (2012) in furfural. Might be down-regulated RND efflux pump encoded genes contributed essestial role against acids resistance. Hence, the effect of acids on above genes involved in RND efflux pump system is poorly studied needs to be studied their function in detail. Chemotaxis is a bacterial mechanism in response to chemical stimuli. A chemotaxis protein CheA, ZMO_RS00345 was down-regulated in ZM4 while CheB ZMO_RS03930 was up-regulated in ZM532 under acidic conditions. Flagellum-related proteins (ZMO_RS02810 (flF), ZMO_RS02680 (motA), ZMO_RS02770 (flhA), ZMO_RS02705), cell division protein (ZMO_RS01795) protein were down-regulated in both ZM4 and ZM532 in our proteome data. Interestingly, ZMO_RS02795 (flagellin), ZMO_RS02890 (flagellar protein FliS), ZMO_RS02760 (flgM), ZMO_RS02720 (flagellar hook-basal body complex protein), ZMO_RS02685 (Flagellin) were up-regulated in ZM532 (Additional file 14: Table S14). Up-regulation of these proteins may be tolerance mechanism to acetic acid and furfural. It should be noted, however, that the effect of acids on the above mentioned genes and proteins are raely discussed. In our transcriptome we found a number of genes (ZMO_RS02675, ZMO_RS02680, ZMO_RS00870, ZMO_RS02690, ZMO_RS02825, ZMO_RS02700) encoding proteins associated with chemotaxis and flagellar structure were significantly down-regulated under the acidic condition in both strains (Additional file 7, 8: Table S7, S8). Our results showed that many genes associated with flagellar assembly and chemotaxis were reserved. Limiting flagellum biosynthesis is an energy usage technique to reserve the comparatively expensive energy reserve in stress conditions. Moreover, proteins associated with chemotaxis and flagellum were downregulated in $E$. coli under low-pH conditions and high-osmolality decreasing the flagellum biosynthesis resulting in limited proton penetration [42].

Pentacyclic triterpenoid lipids are class of hopanoids responsible for regulating and maintaining membrane stability, fluidity, $\mathrm{pH}$, homeostasis and membrane integrity in Gram-positive and Gramnegative bacteria [44]. In the current study, proteins associated with hopanoid and terpenoid biosynthesis pathways ( $h p n J$ and $d x s$ ) were down-regulated in both ZM532 (mutant) and ZM4 (wild-type) (Additional file 14: Table S14). Similarly in transcriptome, hopanoid genes (ZMO_RS03910, ZMO_RS04350, ZMO_RS07175) were down-regulated in ZM532 and ZM4 while ZMO_RS03920 was up-regulated in ZM4 (Additional file 7, 8: Table S7, S8). Previously, IspG, Dxs1, and IspA of ZM4 under ethanol stress were down-regulated [24, 26, 27, 45], and similar pattern was recorded in our study under stress conditions. However, acetic acid and furfural stressors may cause detrimental effect on terpenoid biosynthesis and stability of cell membrane. 


\section{TatD is a DNA repair exonuclease contributed acid resistance}

In additition, ZMO_RS04890, encoded TatD family hydrolase were up-regulated gene in mutant strain ZM532 and was absent on wild-type strain ZM4 under acidic condition may crucial against acids resistance. Follow-up studies further showed that TatD bears $3^{\prime}-5^{\prime}$ exonuclease activity that processes single-stranded DNA in DNA repair (Fig. 6G; Additional file 7, 8: Table S7, S8) and participates in DNA fragmentation during apoptosis in S. cerevisiae [46] and Trypanosoma brucei [47]. Previous study showed that TatD-knockout cells are less resistant to the DNA damaging agent hydrogen peroxide [48]. Hydrogen peroxide may induce various DNA lesions, not only double-strand breaks, but also oxidation and deamination of bases and sugar modifications $[49,50]$. TatD has ability to remove deaminated nucleotide from DNA chain, inferring that it may be involved in $\mathrm{H}_{2} \mathrm{O}_{2}$-induced-DNA repair [48]. Since TatD is an evolutionarily conserved protein, it should have an important cellular role. However, our understanding of this protein is largely hampered due to lack of knowledge of its biological functions and structure-to-function relationship. So, in the future, we can provide evidence that TatD is a $3^{\prime}-5^{\prime}$ exonuclease that may process single-stranded DNA in DNA repair.

\section{Contribution of OstA in furfural and acetic acid tolerance}

ZMO_RS01205, ostA encoded organic solvent tolerance protein was up-regulated gene in mutant strain ZM532 and absent in wild-type strain ZM4 under stress condition (Additional file 7, 8: Table S7, S8; Table S14). An earlier studies reported gene ostA is one of the genes contributing to the level of organic solvent tolerance $[51,52]$. In the future, it will be critical to investigate the single and combined effects of genes on the increase in Ost activity in response to salt and acid stress. The overexpression of previously reported transcriptional regulator proteins may be one of most effective method for increasing the Ost of Z. mobilis and other microorganism. Moreover, It will also assist to identify the transcriptional regulator proteins which are important in the Ost mechanisms in ZM4.

\section{Candidate genes and proteins involved in energy generation and conservation}

Transmembrane ATPases decompose ATP into ADP to release energy for importing cell metabolism compounds and exporting the contaminants to inhibit cellular processes. In our transcriptomics data, ATP synthase family proteins such as ZMO_RS01070, ZMO_RS04090, ZMO_RS01900 were up-regulated in ZM532 and ZM4 but their expressions were higher in ZM532 than ZM4. Also, ZMO_RS04930 and ZMO_RS05235 were up-regulated exclusively in ZM4 under the acid inhibitions (Additional file 7, 8: Table S7, S8). Bacteria can increase the activity of $\mathrm{H}^{+}$-ATPase in the presence of acids to reduce proton loss. In bacteria, protons are observed to be transported from cells via $\mathrm{H}^{+}$-ATPase, an ATP-consuming process [43]. As a result, increased $\mathrm{H}^{+}$-ATPase activity and energy accumulation improve cells' ability to regulate $\mathrm{pHi}$ homeostasis under stress environment. Hence, the up-regulation of genes may helful to $\mathrm{H}^{+}$pump out from the cytoplasm by using ATP as previously reported by Rutkis et al. [53] and Yang et al. [40], 
respectively. Our ATP synthase family up-regulated proteins results are inline with these results. In the proteomics data, ZMO_RS01435 which encodes ATPases was up-regulated exclusively in ZM532 while ZMO_RS02975 (encoding F0F1 ATP synthase subunit C) was up-regulated only in ZM4 (Additional file 14: Table S14). The F1Fo ATP synthase can be used to activate and hydrolyze ATP to pump $\mathrm{H}^{+}$for intracellular $\mathrm{pH}$ homeostasis $[54,55]$. Additionally, a previous study revealed F1F0 ATPase hydrolyzes ATP to pump protons when respiration is disrupted culminating in intracellular neutral phase retention of the mitochondrial membrane [56]. Moreover, proteins involved in the respiratory chain for energy production like fldA, ZMO_RS07890, gloB and wrbA were up-regulated with higher expression levels in ZM532 than ZM4 (Additional file 14: Table S14). The transcriptome profile indicates ZMO_RS04970, ZMO_RS03175, ZMO_RS04970 were up-regulated in both strains and are involved in respiratory chain for energy production while ZMO_RS06760, ZMO_RS07025 and ZMO_RS02530 were down-regulated (Additional file 7, 8: Table S7, S8). Previous studies have confirmed that these proteins are essential of higher ethanol production and growth [42] however, up- and down-regulation of genes involved in various biological processes in response to various stressors.

\section{Upregulation of ferredoxin promote high proton transport capacity against acids stressors}

Ferredoxin ( $\mathrm{Fdx}$ ) refers to a class of small proteins that bind inorganic clusters containing two to four iron atoms and an equal number of sulfur atoms [57]. The whole-genome sequencing of bacteria and archaea has uncovered number of genes encoding these proteins [58]. Fdxs are typically ascribed to electron transport activities, and some of them are necessary for metabolism to work properly [59], However, the majority of Fdxs' functions are yet unknown $[60,61]$. Our transcriptome results demostrated ferredoxin encoding genes (ZMO_RS08175 and ZMO_RS00940) was down-regulated in ZM4 and ZM532 under acetic acid and furfural conditions. Down-regulated genes linked to electron transfer chain can make it difficult for protons excretion against proton gradient from the cytoplasm under acidic condition, and thus inhibiting bacterial growth. ZMO_RS07885 was up-regulated in ZM4 under acidic condition (Additional file 7, 8: Table S7, S8) which may an indication of high proton transport capacity against acetic acid and furfural conditions.

\section{Candidate genes and proteins involved in macromolecule repair enhanced resistance and overcome acidic destructions}

In microbes, macromolecule recombination, replication, and repair are central molecular mechanisms for the regulation, and maintenance of genetic information. Bacterial protein, cell membrane, and DNAs are usually damaged under acidic conditions. Repair and resistance proteins such as RecF, UvrA, Hfq, UVRB, UVRC and PPK could be improved to overcome these acidic destructions of macromolecules. Our transcriptomics results showed that ZMO_RS07130 (uvrA) transcription level and its subunits, ZMO_RS01550 (uvrB) and ZMO_RS02990 (uvrB) were up-regulated in both ZM4 and ZM532 under furfural and acetic acid conditions (Fig. 6D; Additional file 7, 8: Table S7, S8). Previous study confirmed 
that overexpression of uvrA in Acetobacter pasteurianus, an extensively used vinegar-brewing acetic acid bacteria, it improved acetic acid tolerance and fermentation [62]. Ultimately, it improved damaged proteins and DNA caused by acids stress. We also found DNA repair genes such as ZMO_RS07115 $(R e c F), Z M O \_R S 05530$ (Recj), DNA mismatch repair enzyme mutL (ZMO_RS01515) and ExoVII (ZMO_RS03825) were up-regulated with higher expression levels in ZM532 than ZM4. This indicates $Z$. mobilis and ZM532 (mutant) could reduce DNA damage caused by furfural and acetic acid by activating relevant genes or DNA replication, base repair and recombination. Our results are in line with previously reported [27, 41, 42]. We also found ZMO_RS03175 (ppk) and ZMO_RS00830 (Hfq) were up-regulated in ZM532 (mutant) and ZM4 under acetic acid and furfural stress which is consistent with findings of previous studies [26, 27, 41]. Hfq is an RNA-binding protein and plays significant roles in bacterial gene expression regulation. It is also linked to Rho motor protein in E. coli for initiation of transcription antitermination by novel transcription regulatory mechanisms [63-65]. tudies demonstrated that $H f q$ may play a crucial role in sRNA network regulation $[66,67]$. Several recent studies indicate that $Z$. mobilis $h f q$ responds inhibitors of lignocellulosic pretreatment, which for the basis for industrial production of the strain $[16,26]$. ppk gene (ZMO RS03175), which encodes RNA degradosome polyphosphate kinase, as well as previous research in other bacteria, demonstrated that polyP is rapidly accumulated by $P P K$ under environmental stress (acidic conditions) [68-70]. The upregulation of ppk in wild-type ZM4 and mutant strains under furfural and acetic acid stresses are consistent with these results (Additional file 7, 8: Table S7, S8).

Our proteome profiling revealed ZMO_RS00935 (helicase domain protein), ZMO_RS01550, (excinuclease ABC subunits UVrB) were up-regulated in ZM4; while UVrA (ZMO_RS00655) was up-regulated in both ZM4 and ZM532 under acetic acid and furfural conditions (Additional file 14: Table S14). However, ZMO_RS00535 (S1/P1 nuclease ZM00127, helicase domain protein ZM00219, ZMO_RS00975 (DNA polymerase I, PolA), ZMO_RS06345 (DEAD/DEAH box helicase domain protein), ZMO_RS07380 (recG), ZMO_RS03620 (recR) were down-regulated under the acidic stress conditions (Additional file 14: Table S14). Up-regulation of these proteins is important for cell recovery from DNA damage caused by these inhibitors.

In the current study, transcriptional response regulatory proteins ZMO_RS05270, YebC/PmpR family DNAbinding transcriptional regulator (ZMO_RS00645), TetR family transcriptional regulator (ZMO_RS06920), phosphate regulon transcriptional regulatory protein PhoB (ZMO_RS05215), transcription anti-termination factor NusB (ZMO_RS06945) and transcriptional response regulator (ZMO_RS05270) were up-regulated exclusively in ZM532. The SUF system, Fe-S cluster assembly regulator (ZMO_RS01820) was upregulated exclusively in ZM4 (Additional file 14: Table S14).

Proteins associated with translation, ribosomal structure and biogenesis such as greA (ZMO_RS07250) elongation factors, raiA (ZMO_RS00175), ZMO_RS05165 (ribosome recycling factor), ZMO_RS04425 ( $d k s A$ ) were up-regulated in both ZM4 and ZM532 while ybeY (ZMO_RS00305) and tsaE (ZMO_RS04930) were up-regulated only in ZM532. However, several proteins such as tilS (ZMO_RS07450), ZMO_RS03355, trmB (ZMO_RS00625), rnc (ZMO_RS06145), ZMO_RS06475, and ZMO_RS02190 were down-regulated 
under the stress conditions (Additional file 14: Table S14). This is in agreement with the transcriptomic results of furfural, and acetate-challenged $Z$. mobilis $[26,42,71]$. Down-regulation of these proteins suggests the overall synthesis of proteins to minimize cell growth [26]. This may be attributed in part to external stress that causes mRNA degradation and inhibits the translation process [72].

\section{Candidate genes and proteins involved in chaperones participate in resistance}

Proteins associated with posttranslational alteration, protein turnover, and molecular chaperone complex responsive to stress shock could react to various stress conditions, including extreme temperature, depletion of cellular resources, concentrations of ions and toxic substances [73]. Transcriptional level of ZMO_RS02930, Novel00004 (dnaK) and ZMO_RS08760 encode GroEL protein for adaptation to acidic stress [41]. This protein (GroEL protein) was however, highly expressed in ZM532 than in ZM4. An earlier study revealed that $d n a \mathrm{~K}$ is crusical for microbe survival in evironmental stress conditions [74] becides, dnak play significant role in refolding of damaged proteins. Two novel genes (Novel00013 and Novel00014), which encode GroEL were up-regulated exclusively in the mutant strain ZM532, which may account for the robustness of our mutant strain against acetic acid and furfural stresses and could lead to high ethanol production (Fig. 6B; Additional file 7, 8: Table S7, S8). Previous studies have confirmed that these proteins are necessary for normal growth of $E$. coli under toxic antibiotic $[11,26]$ and temperature stress conditions [75]. Our transcriptomics result showed that the expression level of Clp protease complex, like ZMO_RS01740 (clpA), ZMO_RS04250 (ATP-dependent Clp protease proteolytic subunit), ZMO_RS04255 (clpX), ZMO_RS06375 (clpB), and ZMO_RS07775 (clpS) were up-regulated in both ZM4 and mutant ZM532 but the expression level of Clp protease were higher in mutant ZM532 compared with ZM4 (Fig. 6B; Additional file 7, 8: Table S7, S8). These may be involved in protein remodeling and reactivation $[41,76-78]$ to enhance the expression of these proteins to protect DNA and protein from damage in acidic cytoplasm. However, our transcriptomics results demonstrated that sulfur encoding genes (ZMO_RS00040, ZMO_RS06540, ZMO_RS00045 ZMO_RS03345, and ZMO_RS00025) were up-regulated in ZM532 and ZM4 but their expressions were higher in ZM532 compared to ZM4 (Fig. 6E; Additional file 7, 8: Table S7, S8). As furfural and acetic acid could inhibit sulfhur amino acid biosynthesis either by restricting the availability of reduced sulfur $\left(\mathrm{H}_{2} \mathrm{~S}\right)$ from sulfate or by inhibiting the incorporation of reduced sulfur into cysteine. The inhibition of sulfate reduction is unlikely to represent the initial action of furfural that inhibits growth [79]. Up-regulation of these genes may have contributed to the improved tolerance of $Z$. mobilis to acetic acid and furfural stressors.

Our proteomics data showed that molecular chaperone complexes (ZMO_RS06375 (ClpB), ZMO_RS01740 (ClpA)) were up-regulated in both strains (Additional file 14: Table S14). This contradicts results of previous studies [27]. Such proteins belong to the multi-chaperone system induced by stress, essential for the folding of newly synthesized polypeptides. Another chaperone protein, ZMO_RS04435 (Hsp20 family protein) which regulates bacteria growth and survival under different stresses was upregulated in the mutant ZM532. Hsp20 was found to stabilize both archaeal and bacterial membrane lipids and small HSPs in microbial pathogenesis [80-83]. However, chaperone ZMO_RS03810 
(peptidylprolyl isomerase) which can maintain overall reduction in the level and folding of OMPs and to the induction of the periplasmic and ZMO_RS07675 (tetratricopeptide repeat protein) involves sensing and treatment of defective or incomplete protein structures under stress responses as previously discussed $[82,83]$ both proteins exclusively found only in mutant strain ZM532. For inhibitor tolerance of $Z$. mobilis cells, control of these stress response molecular chaperones may indeed be helpful.

ZMO_RS01850 (iron-sulfur cluster assembly accessory protein) was up-regulated which may assemble or fix oxygen-labile FeS clusters from extracellular iron chelators under oxidative stress and iron uptake (Additional file 14: Table S14). ZMO_RS08485 (grxD), ZMO_RS03370 (grxC), and ZMO_RS04910 (thioredoxin) bind FeS clusters and transport the clusters to specific enzymes. The enzymes were upregulated in both strains (ZM4 and mutant ZM532). ZMO_RS04910 (thioredoxin) was exclusively upregulated in ZM532; essential as electron carrier and antioxidant defense in response to oxidative stress to keep cellular oxidative-antioxidant homeostasis [84].

\section{Candidate genes and proteins involved in central carbon metabolism participated in robustness and increase ethanol production}

The most critical part of living organisms is carbon metabolism. Up-regulated proteins are involved in the ED and TCA cycle routes in the central carbon metabolism pathway. Although only one mole of ATP per single mole of glucose is provided by the ED route, the ED pathway in Z. Mobilis is almost twice the thermodynamically favorable pathway of Embden-Meyerhof-Parnas (EMP) in E. Coli or S. cerevisiae [85]. Up-regulated proteins, Pgk, gpmA and ZMO_RS07905 (glucokinase) were found only in mutant strain ZM532 in our proteomics data while pgl was up-regulated in both strains (Additional file 14: Table S14). Moreover, alcohol dehydrogenase encoded ZMO_RS07165 and ZMO_RS05560 which were up-regulated in both strains but these genes were doubly expressed in ZM532 compared to ZM4. Lactoylglutathione lyase (ZMO_RS03400), hydroxyacylglutathione hydrolase (ZMO_RS03395), 2-hydroxyacid dehydrogenase (ZMO_RS05565), glucose-6-phosphate isomerase (ZMO_RS05445), galactose-1epimerase (ZMO_RS03970), and glucose-6-phosphate isomerase (ZMO_RS05445) were up-regulated in ZM532. These genes may partly account for the robustness of our mutant strain ZM532 against acetic acid and furfural stresses (Fig. 6C; Additional file 7, 8: Table S7, S8). The up-regulation of these genes stimulate more ATPs for acidic tolerance as established by previous reports [41, 42].

\section{Role of porin in acid resistance}

We identified up-regulated gene ZMO_RS08390, encoding carbohydrate porin when compared to resistance strain with wild-type (AF_ZM532 vs AF_ZM4) (Fig. 6H). Porins are proteins present on the outer membrane of bacteria cell wall that have a role in the regulation of cellular permeability and drug resistance [86]. However, number of studies on porin resistance to antibiotics are available [87, 88], a systematic approach to porin roles in ZM4 physiology and acid resistance (acetic acid and furfural) does not exist yet.

Porins primary natural function is to transport polar nutrients, such as amino acids, carbohydrates, and other ions [89]. Moreover, porins played an important role in Gram-negative bacterial envelope integrity by 
facilitating the passive transport of various chemicals. For example, non-specific porins, such as OmpA, found in outer membrane proteins, promote the passive transport of many small molecules [90, 91]. Additionally, this protein is related to peptidoglycan via a flexible periplasmic motif that interacts noncovalently with peptidoglycans [92]. Because porins are linked to antibiotic resistance in Gram-negative bacteria because they enable the passive diffusion of drugs throughout the outer membrane. Although prior research suggested that porins regulate the antibiotic resistance, but contribution of porin in resistance to acids (furfural and acetic acid) largely unknown and not studied yet.

\section{Candidate genes and proteins involved in amino acid biosynthesis pathway}

Amino acids are essential for many biological processes as significant primary metabolites including boosting resistance of yeast cells to various inhibitors [93]. Amino acids biosynthesis-related proteins such as ZMO_RS08080 (aroA), ZMO_RS06730 (hisA), ZMO_RS05085 (serB), ZMO_RS01865 (arginase) and ZMO_RS05275 (hisl) were up-regulated in both strains as evidenced by our proteomics data (Additional file 14: Table S14). However, ZMO_RS01865 (NAD(P)-dependent oxidoreductase), ZMO_RS05705 (threonine), ZMO_RS00475 (pabB), ZMO_RS01920 (SGNH/GDSL), ZMO_RS08995 (panB), ZMO_RS02925 (HAD-IB family hydrolase), ZMO_RS04575 (type III PLP-dependent enzyme), ZMO_RS00010 (aminotransferase class I/Il-fold pyridoxal phosphate-dependent enzyme), ZMO_RS06435 (lysE), ZMO_RS00010 (aminotransferase), ZMO_RS06235 (N-formyl glutamate amidohydrolase), ZMO_RS02495 (pyridoxal phosphate-dependent aminotransferase) were down-regulated as previously reported [42].

In addition, our transcriptomics data showed amino acids such as histidine, cysteine, arginine, and serine were differentially expressed under acetic acid and furfural stresses. The genes encoding histidine include ZMO_RS05290, ZMO_RS05275, ZMO_RS02495, ZMO_RS05250 (succinyl arginine dihydrolase), and ZMO_RS03345 (cysteine synthase A) were up-regulated in both strains and in line with [79]. However, ZMO_RS05290 and ZMO_RS02495 were only found in the mutant ZM532 (Fig. 6F; Additional file 7, 8: Table S7, S8). The up-regulation of these genes in the mutant ZM532 may enhance tolerance to acid stresses. Previous studies also confirmed that tolerance of $E$. coli to furfural can be improved significantly by serine, arginine, histidine and aromatic amino acids [79]. Arginine and lysine can also enhance Salmonella typhimurium's resistance to acetic acid stress [94].

\section{Validation of differentially expressed genes under inhibitory (AF) conditions by $\mathrm{qPCR}$}

The results of qPCR showed three DEGs (ZMO-RS02740, ZMO-RS00080, and ZMO-RS08110) were upregulated in ZM532 while ZMO-RS03395, ZMO-RS08600 and ZMO-RS06525 were down-regulated in the same strain ZM532. Conversely, among the selected DEGs in ZM4, ZMO-RS00065 and ZMO-RS02800 were up-regulated, while ZMO-RS01385 and ZMO-RS03775 were down-regulated which are in consonance with the transcriptome results (Figure S8; Additional file 7, 8: Table S7, S8). These genes had 
high expression either as up- or down-regulated in RNA-seq results, hence, give clue for their potential for functional validation in our subsequent experiments.

\section{Verification of RNA-seq candidate genes involved in bacteria tolerance mechanism}

DEGs detected in ZM4 or ZM532, ZMO_RS02740 and ZMO_RS06525 in RNA-seq were selected for verification through Type I-F CRISPR-Cas system technology following recommended procedure (Figure S9) [95]. CRISPR-Cas Type I-F edited Z. mobilis revealed that the protospacer-bearing plasmids had significant interference activity. We transferred the DNA cleavage of interest to a PAM-flanking sequence on the chromosome for self-targeting and genome engineering. The ZMO_RS02740 (204 bp) and ZMO_RS06525 (1275 bp) were selected as engineering targets. Plasmids were primarily constructed to import a leader-repeat-spacer-repeat cassette of an artificial CRISPR expression individually (Fig. 7A). A donor DNA comprising of two homology arms for supporting homologous recombination engineered to carry expected mutations to improve the reliability of selected genotypes by self-targeting (Fig. 7B). By using genome engineering plasmids pKO-ZMO_RS02740 and pKO-ZMO_RS06525 (FigureB), both target genes were successfully deleted in ZM4 and ZM532 (Fig. 7C-D). The genotypes of randomly selected transformants in ZM532 and ZM4 were analyzed by colony PCR and Sanger sequencing and confirmed deletion of both genes (Fig. 7C-D).

\section{Cell growth, glucose consumption, and ethanol production of mutant strains $\triangle Z M O \_R S 02740$ and $\Delta$ ZMO_RS06525 under acetic acid and furfural conditions}

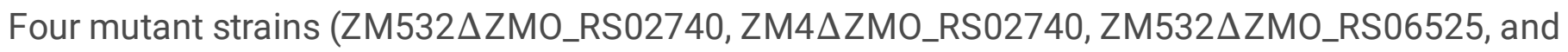
ZM4 $\triangle$ ZMO_RS06525) were investigated under rich media and furfural (3 g/L) with acetic acid (5 g/L) conditions, respectively. Furfural and acetic acid affect glucose consumption, cell growth, and ethanol production (Fig. 8A, B,C and D). With same initial OD600, when strains were cultivated for 36 hours, the ZM4 ZZMO_RS06525 OD600 values was increased by $5.6 \%$ compared with the wild-type strain ZM4 under the same initial OD600. This OD600 value decrease when ZMO-RS02740 was knocked out in ZM532 and ZM4. The growth activity and glucose consumption of mutant strains ZM532 $\Delta$ ZMO_RS02740 and ZM4DZMO_RS02740 were decreased and thus, increasing fermentation time from $42 \mathrm{~h}$ in ZM532 to $55 \mathrm{~h}$. Ethanol production was 58\% higher in ZM532 than that of ZM532 ZMO_RS02740. However, in ZMO_RS06525 knockout in ZM4, time of fermentation was significantly decreased from $60 \mathrm{~h}$ for ZM4 to 42 h for ZM4DZMO_RS06525, which contributed to 45.54\% increase in ethanol production (Table 4). These results demonstrate the mutant ZM532 has more ability to convert sugar to ethanol and to withstand toxic conditions. Moreover, these findings are consistent with our transcriptome data. 
Table 4

Fermentation time of glucose, ethanol titer, yield, and productivity of wild-type ZM4, ZM532 and mutant strains

$50 \mathrm{~g} / \mathrm{L}$ glucose $+5 \mathrm{~g} / \mathrm{L}$ acetic acid $+3 \mathrm{~g} / \mathrm{L}$ furfural

Ethanol

\begin{tabular}{|c|c|c|c|c|c|c|}
\hline Strain & $\begin{array}{l}\text { Fermentation } \\
\text { time (h) }\end{array}$ & $\begin{array}{l}\text { Glucose } \\
\text { consumed } \\
\mathrm{g} / \mathrm{L}\end{array}$ & $\begin{array}{l}\text { Titer } \\
(\mathrm{g} / \mathrm{l})\end{array}$ & $\begin{array}{l}\text { Yield }(\mathrm{g} / \mathrm{g} \\
\text { glucose) }\end{array}$ & $\begin{array}{l}\text { Productivity } \\
(\mathrm{g} / \mathrm{L} / \mathrm{h})\end{array}$ & $\begin{array}{l}\text { Theoretical } \\
\text { value ratio }\end{array}$ \\
\hline ZM532 & 42 & $50.40 \pm 0.86$ & $\begin{array}{l}21.39 \\
\pm 0.57\end{array}$ & $\begin{array}{l}0.424 \pm \\
0.005\end{array}$ & $\begin{array}{l}0.509 \pm \\
0.005^{\star \star}\end{array}$ & $83.13 \%$ \\
\hline $\begin{array}{l}\text { ZM532 } 2 \text { ZM0- } \\
\text { RS02740 }\end{array}$ & 55 & $50.06 \pm 0.17$ & $\begin{array}{l}17.71 \\
\pm \\
0.001\end{array}$ & $\begin{array}{l}0.353 \pm \\
0.01\end{array}$ & $\begin{array}{l}0.322 \pm \\
0.01\end{array}$ & $69.21 \%$ \\
\hline $\begin{array}{l}\text { ZM532 } 2 \text { ZM0- } \\
\text { RS06525 }\end{array}$ & 55 & $50.56 \pm 0.69$ & $\begin{array}{l}17.50 \\
\pm \\
0.057\end{array}$ & $\begin{array}{l}0.346 \pm \\
0.001\end{array}$ & $\begin{array}{l}0.318 \pm \\
0.0007\end{array}$ & $67.84 \%$ \\
\hline ZM4 & 60 & $\begin{array}{l}50.04167 \pm \\
0.23\end{array}$ & $\begin{array}{l}17.57 \\
\pm 0.05\end{array}$ & $\begin{array}{l}0.349 \pm \\
0.01\end{array}$ & $\begin{array}{l}0.292 \pm \\
0.001\end{array}$ & $68.43 \%$ \\
\hline $\begin{array}{l}\text { ZM4 } 4 \text { ZMO- } \\
\text { RS02740 }\end{array}$ & 55 & $50.24 \pm 0.63$ & $\begin{array}{l}17.37 \\
\pm 0.1\end{array}$ & $\begin{array}{l}0.345 \pm \\
0.01\end{array}$ & $\begin{array}{l}0.315 \pm \\
0.001\end{array}$ & $61.76 \%$ \\
\hline $\begin{array}{l}\text { ZM4 } 4 \text { ZMO- } \\
\text { RS06525 }\end{array}$ & 42 & $\begin{array}{l}50.026 \pm \\
0.55\end{array}$ & $\begin{array}{l}17.87 \\
\pm 0.1\end{array}$ & $\begin{array}{l}0.357 \pm \\
0.01\end{array}$ & $\begin{array}{l}0.425 \pm \\
0.01 * \star \star\end{array}$ & $70 \%$ \\
\hline
\end{tabular}

Values are the means and standard deviations of representative experiment with three technical replicates, and error bars indicated standard deviation, ${ }^{\star \star} p<0.01$, ${ }^{\star \star \star} p<0.001$ represents the difference between the control group and mutants strains

\section{Evaluation of candidate resistance genes under furfural and acetic acid tolerance by complementary study}

Lignocellulose inhibitors are composed of aldehydes such as HMF, furfural, weak acids, particularly acetic acid [11]. Ethanol and the toxicity of these inhibitors are influenced by bacterial cell, lipid structure and fluidity, membrane permeability, and physiological processes, including intake of nutrients, electron transport chain, and absorption and energy transduction [96]. Resistance to these inhibitors is a complex phenotype, which is controlled by mysterious regulatory mechanisms. Synthesis of resistant strains by functional and evolutionary engineering is a valuable way to distinguish genetic elements that are important to the resistance of inhibitors [39]. Four plasmids bearing candidate operons were constructed on the basis of a shuttle vector pEZ15Asp with Ptet as the promoter to investigate the impact of these genetic variants on combined acetic acid and furfural resistance. These plasmid constructs were then separately transferred into competent cells of ZM532 and ZM4, including the empty vector pEZ15Asp as the control. Besides, recombinant strains expression profile were examined in without stress and with stress (acetic acid and furfural) conditions to analyze their effect on cell growth. Since the production of 
ethanol in Z. mobilis is closely linked to cell growth and substantially reduced by the inhibitory effects of toxic compounds [97]. Hence, these results suggested that the of ZM406525 encoding a major facilitator superfamily (MFS) containing recombinant strain failed to contribute to the resistance of acids in $Z$. mobilis and ZM532, which is consistent with our RNA-Seq outcome (Fig. 8F). Many major facilitator superfamily transporters are essential for microorganisms to grow under stress conditions. Several superfamily transporters of major facilitators are important for microorganisms to develop under conditions of stress [98]. Gram-negative bacteria can reduce their entry by establishing a low permeability barrier to restrict the intracellular concentration of toxic inhibitors [99]. This non-specific phenomenon, such as the down-regulation of ZM006525, which encodes a major facilitator superfamily (MFS) transporter protein was present in ZM4;while all strains had approximately similar growth rates under normal conditions (Fig. 8E). In addition, the up-regulated expression of ZMORS02740 (Chemotaxis protein Mot A) was similar to our RNA-seq results (Fig. 8F). For the Ptet promoter, the fermentation time of ZMORS02740 was reduced as compared to mutant strain ZM532, which may be ZMORS02740 coordination with some other genes and linker genes for acids resistance. When we combined this gene with Ptet promoter, their balance was disturbed resulting in reduced fermentation time. Our mutant strain ZM532 had a higher hydrolysate metabolic performance in comparison to the parental one and other recombinant strains. This suggests that one gene is may not be adequate to explain the tolerance of acids, and the synergetic effects of several mutations influencing protein structural modifications.

\section{Conclusion}

One of the main challenges of cost-competitive production of bioethanol from lignocellulosic biomass is development of resistant strains toward stresses. Exploitation of the global regulatory landscape may show different impacts on bacterial metabolism leading to the overlap of cell stress responses. In our previous study we constructed a mutant ZM532 by genome shuffling, which is superior to the parental strain and $Z$. mobilis. However, the molecular mechanisms underlying the enhanced tolerance and shortened fermentation time was largely unknown. Therefore, genetic changes, proteins and gene expression profile under AF (acetic acid and furfural) stress or without stress conditions were investigated using transcriptomics and proteomics to unravel the molecular mechanisms in the wild type (ZM4) and mutant strain (ZM532). We also studied the functions of differentially expressed genes and proteins, and their relevant role in tolerance mechanism against inhibitors using the GO and KEGG databases. Our results revealed that the strain, ZM532 is more capable of converting biomass to ethanol; and enhanced fitness in the toxicant-containing environment will benefit from this. Thus, ZM532 can be used to enhance bioethanol production under acetic acid and furfural conditions with ZM4 as a biocatalyst within a shorter fermentation period and greater productivity than ZM4. Overall, the $Z$. mobilis furfural and acetic acid tolerance molecular mechanism presented in this study may useful to synthetic biology focused on enhancing biological processes involved in ethanol production.

\section{Material And Methods}




\section{Bacterial strains and fermentation conditions}

In this study, Z. mobilis, ZM4 and its mutant ZM532 were used. Both strains were cultivated on Rich Medium (RM) containing agar plates at $30^{\circ} \mathrm{C}[100]$. All cell culture plates were incubated at $30^{\circ} \mathrm{C}$ until colonies were grown and stored at $4^{\circ} \mathrm{C}$. Then, both strains were cultured in $\mathrm{RM}$ at $30^{\circ} \mathrm{C}$ without shaking for $16 \mathrm{~h}$ [100]. The strains were sub-cultured to fresh inoculum RM media or on RM plates added to agar power for $16 \mathrm{~h}$ at $30^{\circ} \mathrm{C}$. Inoculation into fermentation medium was conducted when the initial cell density of optical density $600\left(\mathrm{OD}_{600}\right)$ for ZM4 and ZM532 were between 0.1 and 0.2 . Cell pellets were extracted by centrifugation at $3,000 \times \mathrm{g}$ for $4 \mathrm{~min}$ at $4^{\circ} \mathrm{C}$ and then inoculated in groups without inhibitors for 8 hours and with inhibitors (acetic acid and furfural) for 36 hours fermentation period. Both fermentations and cultring were performed in triplicates. The groups of ZM4 and ZM532 susceptible to acetic and furfural acids combination were named as AFZM4, and AF532, respectively, while other groups without inhibitors, the cells grown in RM were considered as control groups designated as RMZM4 and RM532. Based on previous experiment, the concentrations of acetic acid and furfural combinations were set at $5.0 \mathrm{~g} / \mathrm{L}$ and $3.0 \mathrm{~g} / \mathrm{L}$ to study the responses of ZM4 and mutant ZM532 [10]. The cells at exponential growth phase of ZM532 and ZM4 were collected. The cell pellets collected were used for subsequent experiments.

\section{Genomic DNA isolation, amplification of 16S rRNA by PCR and genome re-sequencing}

ZM532 and ZM4, $5 \mathrm{~mL}$ of cells were harvested from overnight culture by centrifugation at 13,500 rpm for genomic DNA (gDNAs) extraction via Bacterial DNA Kit (Omega, Bio-tek, USA). The quality and concentration of gDNAs were estimated by Qubit 3 Fluorometer and gel electrophoresis $(0.25 \%$ agarose, $120 \mathrm{~V} / \mathrm{cm}, 40 \mathrm{~min}$ ), respectively. To ensure that the ZM532 is associated with Z. mobilis, ZM532 genes were amplified by PCR. From 50uL overnight culture, fresh cells were harvested, washed and resuspended in $10 \mu \mathrm{L}$ of $d_{d H_{2}} \mathrm{O}$. PCR conditions and reactions were set and performed following manufacturer's instructions with minor modifications (Toyobo, Japan) with primers (Additional File 1: Table S1). Amplicons were sent to GENEWIZ Inc. (Chengdu, China) for re-sequencing. After sequencing, BioEdit 7.0 software [101] was used to analyze the data against the reference genome of strain ZM4 (NC_006526.2) to identify single nucleotide polymorphism (SNP)/indel in ZM532.

\section{RNA extraction, library preparation, and sequencing}

Total RNAs were extracted using the RNA isolation kit from bacteria cells $(2$ strains $\times 2$ conditions $\times 3$ replications) cultured in RM and AF medium (Tiangen, China). The RNA purity, concentration ( $\mathrm{ng} / \mathrm{ul}$ ) and integrity was evaluated using the Nanodrop spectrophotometer (Qubit 2.0, Agilent 2100). Highly qualified RNAs were used for construction and sequencing of cDNA libraries [102, 103]. The high-throughput sequencing was conducted by Illumina Hiseq 2000 platform after passing via a number of screening phases. The transcript sequences of Zymomonas mobilis used for the study have been deposited in the Gene Expression Omnibus (GEO) repository of the National Center for Biotechnology Information (NCBI) (GEO) accession number: GSE168900. 


\section{Reads mapping to the reference genome and quantification of gene expression}

Raw data (raw reads) were interpreted via in-house perl scripts and clean data was extracted by eliminating reads comprising adapters. Then, the clean data of Q20, Q30, and GC content were computed. Complete genome annotation files downloaded from the genome website Bowtie2-2.2.3

(ftp://ftp.ncbi.nlm.nih.gov/genomes/bacteria/Zymomonas_mobilis/) were used to construct a reference genome index and match clean reads to the reference genome [104]. Novel genes, operon and transcription start sites were identified by Rockhopper [22]. Then, extracted the 5'UTR (3'UTR) sequences. Then, RBS finder [105] and TransTermHP ([106] were used to predict SD sequences and terminator sequences, respectively. IntaRNA was used to predict the sRNA targets. And then we used RNAfold to predict RNA secondary structures $[107,108]$. Mapping of clean reads to each gene was counted using HTSeq v0.6.1. The fragments per kilobase of exon per million fragments mapped (FPKM) reads of every single gene were determined as described earlier [109].

\section{Differentially expression genes and functional analyses}

The read counts were modified for each sequenced library by edger software package via one standardized scaling factor. Differentially expression genes (DEGs) analyses of two conditions were performed using the DESeq package in $\mathrm{R}$ (1.18.0) [110]. Then using Benjamini \& Hochberg approach, the p-values were adjusted. Genes with fold change $(F C)>1.5$ and a false discovery rate $(F D R ;<0.05)$ were considered as DEGs. Gene Ontology (GO) and pathway enrichment analyses of the DEGs were implemented with GOseq package in R [111], respectively. $\mathrm{GO}$ terminologies with adjusted p-value less than 0.05 were identified as significantly enriched.

\section{Validation of differentially expressed genes by quantitative PCR}

A quantitative PCR (qPCR) was conducted as previously described [112]. A total of 10 DEGs were used for qPCR and were chosen from the RNA-seq data on the basis of their differential expression patterns in both groups of ZM4 and ZM532. Total RNAs were extracted under AF and RM conditions from ZM4 and ZM532 via the Qiagen 74101 RNeasy Mini Kit and assessed as directed by the manufacturer. The first strand cDNA was produced using the Quick Quant cDNA kit with three biological replicates to perform the expression of ZM4 and ZM532-AF and ZM4 and ZM532-RM by qPCR (BIO-RAD, Richmond, CA, USA). The reaction phase was as follows: denaturation for $15 \mathrm{~min}$ at $95^{\circ} \mathrm{C}$, followed by 40 amplification cycles for $10 \mathrm{sec}$ at $95^{\circ} \mathrm{C}$ and $30 \mathrm{sec}$ at $53^{\circ} \mathrm{C}$. Using the delta-delta- $\mathrm{Ct}\left(2^{-\Delta \Delta \mathrm{Ct}}\right)$ method with $16 \mathrm{~S}$ RNA as a reference control, relative gene expressions were computed (Additional File 2: Table S2). The student ttest $(p<0.05)$ was used for mean comparisons. Results was shown in bar chart with the means and their standard deviation $(\mathrm{M} \pm \mathrm{SD})$.

\section{Total protein extraction and protein quality test}


Samples ( 2 strains $\times 2$ conditions $\times 3$ replications) were independently ground in liquid nitrogen and lysed with a lysis buffer (consisting of $6 \mathrm{M}$ Urea and $0.2 \% \mathrm{SDS}, 100 \mathrm{mM} \mathrm{NH}_{4} \mathrm{HCO}_{3}, \mathrm{pH} \mathrm{8.0)}$ ), accompanied by 5 min of ice ultrasound. At $12000 \mathrm{~g}$ for $15 \mathrm{~min}$ at $4^{\circ} \mathrm{C}$, the lysate was centrifuged and the supernatants transmitted to a clean tube. The extracts from each sample were reduced to $10 \mathrm{mM} \mathrm{DTT}$ for $1 \mathrm{~h}$ at $56^{\circ} \mathrm{C}$ and alkylated with iodoacetamide under dark room temperature for 1 hour. Samples were thoroughly vortexed with $4 x$ the volume of precooled acetone and incubated at $-20^{\circ} \mathrm{C}$ for at least 2 hours. Samples were then centrifuged and precipitated. They were washed twice with cold acetone and pellets were dissolved with a dissolution buffer of $0.1 \mathrm{M}$ triethylammonium bicarbonate (TEAB, pH 8.5) and $6 \mathrm{M}$ urea [113-115].

\section{Label-free quantitative protein analysis}

The result of each fractions were searched separately by the search engines for Z.-mobilis-NCBI databases: Proteome Discoverer 2.2. (PD 2.2, Thermo). The search parameters were set as follows: the tolerance of precursor ion mass was $10 \mathrm{ppm}$, and the tolerance of product ion mass was 0.02 Da. Carbamidomethyl was mentioned in PD 2.2 as a fixed amendment. Oxidation of methionine (M) and acetylation of N-terminus were identified in PD 2.2 as variable modifications. A maximum of 2 missing cleavage sites were allowed. At least 1 distinct peptide with no more than $1.0 \%$ FDR contains the protein identified. Related peptides that could not be identified by an MS/MS analysis were categorized in the same category of proteins. Based on the intensity used for label-free quantification, precursor ions were quantified using a label-free method. The Mann-Whitney Test for proteins whose quantitation differs significantly between experimental and control groups $(p<0.05$ and $\log 2 \mathrm{FC}>1.5)$ known as were evaluated as the differentially expressed proteins. Gene Ontology (GO) analysis was performed using interproscan-5 programmeagainst a non-redundant protein database (such as Pfam, PRINTS, ProDom, SMART, ProSiteProfiles and PANTHER) [116]. Criteria for analysis of GO and Kyoto Encyclopedia of Genes and Genomes (KEGG) were followed as illustrated by [117]. All sequencing phases were performed by Novogene Sequencing Company (Chengdu, China).

\section{Construction of plasmids, strains and culture conditions}

We selected two genes (ZMO-RS02740 and ZMO-RS06525, encoding Chemotaxis protein Mot A and major facilitator superfamily (MFS) proteins) for verification of their functions in stress tolerance by knock out. We used Type I-F CRISPR-Cas9 system to delete both genes in ZM4 and ZM532. pEZ15Asp was used as backbone vector. sgRNA fragments were ligated with a linear vector $p E Z 15 A s p$ linearized through Gibson assembly method, yielding plasmids Pmini-T-ZMO-RS02740, carrying an artificial miniCRISPR array. Donor DNA fragments containing up stream (ZMO-RS02740, 500bp) gfp marker and its promoter pdc (1020 bp) downstream (ZMO-RS02740, 500bp) regions were obtained by overlap extension PCR amplification using primers. The PCR products were linked with Pmini-T-ZMO-RS02740 vector through Gibson assembly after generating the genome editing plasmid, Pmini-T-ZMO-RS02740. The correct plasmids were electroporated into Z. mobilis (ZM4 and ZM532) competent cell by using previously described method [118]. Transformants were cultured on RM agar plates with spectinomycin $(100 \mu \mathrm{g} / \mathrm{mL})$. After $4-5$ days incubation at $30^{\circ} \mathrm{C}$, positive clones were detected by colony PCR with check 
primer and DNA sequencing (Tsingke, Chengdu, China). Similarly, the plasmids Pmini-T-ZMO-RS06525 plasmid were constructed using the same approach (Additional File 3: Table S3). All DNA manipulation, such as transformation of $E$. coli, preparation of plasmid from E. coli, ligation, digestion of restriction enzyme, and agarose gel electrophoresis were conducted according to standard protocols [119]. Cell growth, ethanol production and glucose consumption by recombinant strains were calculated under furfural $(3.0 \mathrm{~g} / \mathrm{L})$ and acetic acid $(5.0 \mathrm{~g} / \mathrm{L})$ stress conditions.

\section{Analytical methods}

Concentrations of ethanol production and glucose consumption were determined using the Highperformance liquid chromatograph (HPLC, Agilent 1200) with column (HPX-87H) while UV Spectrophotometer was used to estimate the cell density at OD600. Fresh cultures were incubated at 30

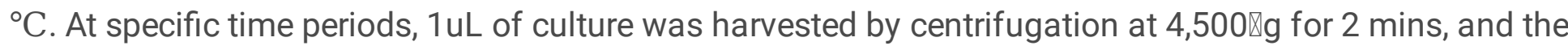
extracts collected and diluted 10 times. HPLC (Agilent 1200) was used to estimate ethanol production and glucose consumption at $0.6 \mathrm{~mL} / \mathrm{min}$ flow rate with $5 \mathrm{mM} \mathrm{H} 2 \mathrm{SO} 4$, and $35^{\circ} \mathrm{C}$ column temperature with $20.0 \mu \mathrm{L}$ volume of injection, respectively.

\section{Evaluation of candidate operons under furfural and acetic acid conditions}

We selected ZMO-RS02740 and ZMO-RS06525 amplified from mutant strain ZM532 and ZM4 genomic DNA by using specific-primers (Additional file 4: Table S4). With Ptet promoter, PCR products were cloned into shutter vector pEZ15Asp [120] via Gibson assembly process [121] using overlapping primers consisting of $18 \sim 20$ nucleotides. With right plasmid constructions, recombinant strains were detected by colony PCR with primer checks and confirmed by Sanger sequencing (Tsingke, Chengdu, China). These control plasmids were named as pEZ15Asp-ZM402740, pEZ15Asp-ZM53202740, pEZ15Asp-ZM406525, and pEZ15Asp-ZM53206525, respectively. While treatment plasmid were named ZM4-02740, ZM53202740, ZM4-06525 and ZM532-06525, respectively. The right plasmids were then transformed into competent ZM532 2 ZMO_RS02740, ZM4DZMO_RS02740, ZM532 2 ZMO_RS06525, and ZM4DZMO_RS06525 mutant cells via electroporation using previously described method [118]. After getting mutants, cell growth were calculated under furfural $(3.0 \mathrm{~g} / \mathrm{L})$ and acetic acid $(5.0 \mathrm{~g} / \mathrm{L})$ stress conditions

\section{Statistical analysis}

According to the statistics, the data was considered significant as the value obtained was $p<0.05$ and the data expression is mean $\pm S D$ (Mean $\pm S D$ ).

\section{Abbreviations}

$\mathrm{AF}$

Acetic acids and furfural

DEGs 
Differentially expressed genes

ED

Entner Doudoroff

mARTP

multi-round atmospheric and room temperature plasma

SNVs

single nucleotide variants

RM

Rich Medium

gDNAs

genomic DNA

$\mathrm{M}$

methionine

AA

amino acid

GO

Gene Ontology

HPLC

High-performance liquid chromatograph

SNPs

Single nucleotide polymorphisms

PCA

principal component analysis

COG

Clusters of Orthologous Groups

KEGG

Kyoto Encyclopedia of Genes and Genomes

IPR

Interpro

DEP

differentially expressed proteins

MBPT

Monofunctional biosynthetic peptidoglycan transglycosylase

MFS

Major facilitator superfamily

EMP

Embden-Meyerhof-Parnas

$\mathrm{NADH}$

Nicotinamide Adenine Dinucleotide (reduced)

HMF 
Hydroxymethylfurfural

OD

Optical Density

CDS

Coding Sequence

\section{Declarations}

\section{Acknowledgements}

This research was financially supported by the National Natural Sciences Foundation of China (Grant No. 32070036), the Elite Program and Basic Research Program of Chinese Academy of Agricultural Sciences, Central Public-interest Scientific Institution Basal Research Fund and Agricultural Science (No. Y2019XK23-01) and Agricultural Science and Technology Innovation Project of Chinese Academy of Agricultural Sciences (CAAS-ASTIP-2016-BIOMA).

\section{Authors' contributions}

MXH designed the whole study and edited the entire draft manuscript. SS participated in all experiments and data collection. BW, WTW and MN participated in manuscript editing. MC, PTL, YHD, LLS, QYG, RBL and GQH participated in HPLC analysis. All authors read and approved the final manuscript.

\section{Conflicts of interest}

The authors declare that they have no competing interests.

\section{Funding information}

This research was financially supported by the National Natural Sciences Foundation of China (Grant No.32070036), the Elite Program and Basic Research Program of Chinese Academy of Agricultural Sciences, Central Public-interest Scientific Institution Basal Research Fund and Agricultural Science (No. Y2019XK23-01) to Mingxiong He.

Supported by Agricultural Science and Technology Innovation Project of Chinese Academy of Agricultural Sciences (CAAS-ASTIP-2016-BIOMA) to Guoquan Hu.

\section{Availability of supporting data}

The Z. mobilis 532 has been deposited at Guangdong Microbial Culture Center (GDMCC) under the Accession Number GDMCC60527. The datasets generated and/or analyzed during the current study are included in this article, its supplementary information files and in the NCBI repository with Accession No: GSE168900 (https://www.ncbi.nlm.nih.gov/geo/query/acc.cgi?acc=GSE168900).

\section{Consent for publication}


Not applicable.

\section{Ethics approval and consent to participate}

Not applicable

\section{References}

1. Hickey LT, Robinson ANH, Jackson H, Leal-Bertioli SA, Tester SCM, Gao M, Godwin C, Hayes ID, Wulff BJ. BBH: Breeding crops to feed 10 billion. Nature biotechnology. 2019;37(7):744-54.

2. Council NR. Climate Change: Evidence, Impacts, and Choices: Set of 2 Booklets, with DVD. National Academies Press; 2012.

3. Kynčlová P, Upadhyaya S, Nice T. Composite index as a measure on achieving Sustainable Development Goal 9 (SDG-9) industry-related targets: The SDG-9 index. Appl Energy. 2020;265:114755.

4. Peters JM, Banta AB, Enright AL, Siletti C: A High-efficacy CRISPRi System for Gene Function Discovery in Zymomonas mobilis. BioRxiv 2020.

5. Parapouli M, Vasileiadis A, Afendra A-S, Hatziloukas E. Saccharomyces cerevisiae and its industrial applications. AIMS microbiology. 2020;6(1):1.

6. Qiu M, Shen W, Yan X, He Q, Cai D, Chen S, Wei H, Knoshaug EP, Zhang M, Himmel ME. Metabolic engineering of Zymomonas mobilis for anaerobic isobutanol production. Biotechnology for biofuels. 2020;13(1):15.

7. Carreón-Rodríguez OE, Gutiérrez-Ríos RM, Acosta JL, Martinez A, Cevallos MA. Phenotypic and genomic analysis of Zymomonas mobilis ZM4 mutants with enhanced ethanol tolerance. Biotechnology Reports. 2019;23:e00328.

8. Kim D. Physico-chemical conversion of lignocellulose: Inhibitor effects and detoxification strategies: A mini review. Molecules. 2018;23(2):309.

9. Wang W-t, Dai L-c, Wu B, Qi B-f, Huang T-f. Hu G-q, He M-x: Biochar-mediated enhanced ethanol fermentation (BMEEF) in Zymomonas mobilis under furfural and acetic acid stress. Biotechnology for biofuels. 2020;13(1):1-10.

10. Wang W, Wu B, Qin H, Liu P, Qin Y, Duan G, Hu G, He M. Genome shuffling enhances stress tolerance of Zymomonas mobilis to two inhibitors. Biotechnol Biofuels. 2019;12(1):288.

11. Wu C-J, Lu H-F, Lin Y-T, Zhang M-S, Li L-H, Yang T-C. Substantial contribution of SmeDEF, SmeVWX, SmQnr, and heat shock response to fluoroquinolone resistance in clinical isolates of Stenotrophomonas maltophilia. Frontiers in microbiology. 2019;10:822.

12. Yang S, Fei Q, Zhang Y, Contreras LM, Utturkar SM, Brown SD, Himmel ME, Zhang M. Zymomonas mobilis as a model system for production of biofuels and biochemicals. Microbial biotechnology. 2016;9(6):699-717. 
13. Shui Z-X, Qin H, Wu B, Ruan Z-y, Wang L-S, Tan F-R, Wang J-L, Tang X-Y, Dai L-C, Hu G-Q. Adaptive laboratory evolution of ethanologenic Zymomonas mobilis strain tolerant to furfural and acetic acid inhibitors. Appl Microbiol Biotechnol. 2015;99(13):5739-48.

14. Yi X, Gu H, Gao Q, Liu ZL, Bao J. Transcriptome analysis of Zymomonas mobilis ZM4 reveals mechanisms of tolerance and detoxification of phenolic aldehyde inhibitors from lignocellulose pretreatment. Biotechnology for biofuels. 2015;8(1):153.

15. Yang S, Land ML, Klingeman DM, Pelletier DA, Lu T-YS, Martin SL, Guo H-B, Smith JC, Brown SD: Paradigm for industrial strain improvement identifies sodium acetate tolerance loci in Zymomonas mobilis and Saccharomyces cerevisiae. Proceedings of the National Academy of Sciences 2010, 107(23):10395-10400.

16. Yang S, Pelletier DA, Lu T-YS, Brown SD. The Zymomonas mobilis regulator hfq contributes to tolerance against multiple lignocellulosic pretreatment inhibitors. BMC Microbiol. 2010;10(1):135.

17. Wu B, Qin H, Yang Y, Duan G, Yang S, Xin F, Zhao C, Shao H, Wang Y, Zhu Q, et al. Engineered Zymomonas mobilis tolerant to acetic acid and low pH via multiplex atmospheric and room temperature plasma mutagenesis. Biotechnol Biofuels. 2019;12(1):10.

18. Franden MA, Pienkos PT, Zhang M. Development of a high-throughput method to evaluate the impact of inhibitory compounds from lignocellulosic hydrolysates on the growth of Zymomonas mobilis. Journal of biotechnology. 2009;144(4):259-67.

19. Franden MA, Pilath HM, Mohagheghi A, Pienkos PT, Zhang M. Inhibition of growth of Zymomonas mobilis by model compounds found in lignocellulosic hydrolysates. Biotechnology for biofuels. 2013;6(1):1-15.

20. Xu T, Guo X, Wang H, Hao F, Du X, Gao X, Liu D. Differential gene expression analysis between anagen and telogen of Capra hircus skin based on the de novo assembled transcriptome sequence. Gene. 2013;520(1):30-8.

21. Foster JW. Escherichia coli acid resistance: tales of an amateur acidophile. Nat Rev Microbiol. 2004;2(11):898-907.

22. McClure R, Balasubramanian D, Sun Y, Bobrovskyy M, Sumby P, Genco CA, Vanderpool CK, Tjaden B. Computational analysis of bacterial RNA-Seq data. Nucleic acids research. 2013;41(14):e140-0.

23. Yang S, Pan C, Hurst GB, Dice L, Davison BH, Brown SD. Elucidation of Zymomonas mobilis physiology and stress responses by quantitative proteomics and transcriptomics. Frontiers in microbiology. 2014;5:246.

24. Jeon YJ, Xun Z, Su P, Rogers PL. Genome-wide transcriptomic analysis of a flocculent strain of Zymomonas mobilis. Appl Microbiol Biotechnol. 2012;93(6):2513-8.

25. Zhang K, Shao H, Cao Q, He M-x, Wu B, Feng H. Transcriptional analysis of adaptation to high glucose concentrations in Zymomonas mobilis. Appl Microbiol Biotechnol. 2015;99(4):2009-22.

26. He M-x, Wu B, Shui Z-x, Hu Q-c, Wang W-g, Tan F-r, Tang X-y, Zhu Q-I, Pan K, Li Q, et al. Transcriptome profiling of Zymomonas mobilis under furfural stress. Appl Microbiol Biotechnol. 2012;95(1):18999. 
27. He M-x, Wu B, Shui Z-x, Hu Q-c, Wang W-g, Tan F-r, Tang X-y, Zhu Q-I, Pan K, Li Q: Transcriptome profiling of Zymomonas mobilis under ethanol stress. Biotechnology for biofuels 2012, 5(1):75.

28. Wu B, Qin H, Yang Y, Duan G, Yang S, Xin F, Zhao C, Shao H, Wang Y, Zhu Q. Engineered Zymomonas mobilis tolerant to acetic acid and low $\mathrm{pH}$ via multiplex atmospheric and room temperature plasma mutagenesis. Biotechnology for biofuels. 2019;12(1):10.

29. Zhou Q, Zhang X, Xu H, Xu B, Hua Y. RadA: A protein involved in DNA damage repair processes of Deinococcus radiodurans R1. Chin Sci Bull. 2006;51(24):2993-9.

30. Jeong KC, Hung KF, Baumler DJ, Byrd JJ, Kaspar CW: Acid stress damage of DNA is prevented by Dps binding in Escherichia coli 0157: H7. BMC microbiology 2008, 8(1):1-13.

31. Baker AT, Takahashi N, Chandra SB. A Comparative Analysis of Monofunctional Biosynthetic Peptidoglycan Transglycosylase (MBPT) from Pathogenic and Non-pathogenic Bacteria. Genomics Informatics. 2010;8:63-9.

32. Ryan S, Begley M, Gahan CG, Hill C. Molecular characterization of the arginine deiminase system in Listeria monocytogenes: regulation and role in acid tolerance. Environ Microbiol. 2009;11(2):432-45.

33. Yang S, Vera JM, Grass J, Savvakis G, Moskvin OV, Yang Y, Mcllwain SJ, Lyu Y, Zinonos I, Hebert AS, et al. Complete genome sequence and the expression pattern of plasmids of the model ethanologen Zymomonas mobilis ZM4 and its xylose-utilizing derivatives 8b and 2032. Biotechnol Biofuels. 2018;11:125.

34. Gorr TA. Hypometabolism as the ultimate defence in stress response: how the comparative approach helps understanding of medically relevant questions. Acta Physiol (Oxford England). 2017;219(2):409-40.

35. Hung W-C, Chen H-J, Lin Y-T, Tsai J-C, Chen C-W, Lu H-H, Tseng S-P, Jheng Y-Y, Leong KH, Teng L-J. Skin commensal staphylococci may act as reservoir for fusidic acid resistance genes. PLoS One. 2015;10(11):e0143106.

36. Duan G, Wu B, Qin H, Wang W, Tan Q, Dai Y, Qin Y, Tan F, Hu G, He M. Replacing water and nutrients for ethanol production by ARTP derived biogas slurry tolerant Zymomonas mobilis strain. Biotechnology for biofuels. 2019;12(1):1-12.

37. Samantarrai D, Lakshman Sagar A, Gudla R, Siddavattam D. TonB-dependent transporters in Sphingomonads: unraveling their distribution and function in environmental adaptation. Microorganisms. 2020;8(3):359.

38. Fujita M, Mori K, Hara H, Hishiyama S, Kamimura N, Masai E. A TonB-dependent receptor constitutes the outer membrane transport system for a lignin-derived aromatic compound. Communications biology. 2019;2(1):1-10.

39. Zhang K, Lu X, Li Y, Jiang X, Liu L, Wang H. New technologies provide more metabolic engineering strategies for bioethanol production in Zymomonas mobilis. Appl Microbiol Biotechnol. 2019;103(5):2087-99.

40. Yang S, Franden MA, Wang X, Chou Y-C, Hu Y, Brown SD, Pienkos PT, Zhang M. Transcriptomic profiles of Zymomonas mobilis $8 \mathrm{~b}$ to furfural acute and long-term stress in both glucose and xylose 
conditions. Frontiers in microbiology. 2020;11:13.

41. Yang Q, Yang Y, Wang X, Chen Y, Shen W, Tang Y, Zhan Y, Gao J, Wu B, He M. Development and Characterization of Acidic-pH Tolerant Mutants of Zymomonas mobilis through Adaptation and Next Generation Sequencing based Genome Resequencing and RNA-SEq. 2020.

42. Chang D, Yu Z, Islam ZU, French WT, Zhang Y, Zhang H. Proteomic and metabolomic analysis of the cellular biomarkers related to inhibitors tolerance in Zymomonas mobilis ZM4. Biotechnology for biofuels. 2018;11(1):283.

43. Sun J, Deng Z, Yan A. Bacterial multidrug efflux pumps: mechanisms, physiology and pharmacological exploitations. Biochem Biophys Res Commun. 2014;453(2):254-67.

44. Welander PV, Hunter RC, Zhang L, Sessions AL, Summons RE, Newman DK. Hopanoids play a role in membrane integrity and pH homeostasis in Rhodopseudomonas palustris TIE-1. J Bacteriol. 2009;191(19):6145-56.

45. Schmidt A. Einfluß von Ethanol auf die Hopanoidbildung in Zymomonas mobilis: Zentralbibl. d. Kernforschungsanl. Jülich; 1988.

46. Qiu J, Yoon J-H, Shen B. Search for apoptotic nucleases in yeast: role of Tat-D nuclease in apoptotic DNA degradation. J Biol Chem. 2005;280(15):15370-9.

47. Gannavaram S, Debrabant A. Involvement of TatD nuclease during programmed cell death in the protozoan parasite Trypanosoma brucei. Mol Microbiol. 2012;83(5):926-35.

48. Chen Y-C, Li C-L, Hsiao Y-Y, Duh Y, Yuan HS. Structure and function of TatD exonuclease in DNA repair. Nucleic acids research. 2014;42(16):10776-85.

49. Rath D, Mangoli SH, Pagedar AR, Jawali N. Involvement of pnp in survival of UV radiation in Escherichia coli K-12. Microbiology. 2012;158(5):1196-205.

50. Akagawa M, Suyama K. Oxidative deamination by hydrogen peroxide in the presence of metals. Free Radic Res. 2002;36(1):13-22.

51. Aono R, Negishi T, Nakajima H. Cloning of organic solvent tolerance gene ostA that determines nhexane tolerance level in Escherichia coli. Appl Environ Microbiol. 1994;60(12):4624-6.

52. Ohtsu I, Kakuda N, Tsukagoshi N, Dokyu N, Takagi H, Wachi M, Aono R. Transcriptional analysis of the ostA/imp gene involved in organic solvent sensitivity in Escherichia coli. Biosci Biotechnol Biochem. 2004;68(2):458-61.

53. Rutkis R, Strazdina I, Balodite E, Lasa Z, Galinina N, Kalnenieks U. The low energy-coupling respiration in Zymomonas mobilis accelerates flux in the Entner-Doudoroff pathway. PLoS One. 2016;11(4):e0153866.

54. Capaldi RA, Aggeler R. Mechanism of the F1F0-type ATP synthase, a biological rotary motor. Trends Biochem Sci. 2002;27(3):154-60.

55. Liu Y, Tang H, Lin Z, Xu P. Mechanisms of acid tolerance in bacteria and prospects in biotechnology and bioremediation. Biotechnology advances. 2015;33(7):1484-92. 
56. Panicucci B, Gahura O, Zíková A. Trypanosoma brucei TbIF1 inhibits the essential F1-ATPase in the infectious form of the parasite. PLoS Negl Trop Dis. 2017;11(4):e0005552.

57. Meyer J. Iron-sulfur protein folds, iron-sulfur chemistry, and evolution. J Biol Inorg Chem. 2008;13(2):157-70.

58. Andreini C, Banci L, Bertini I, Elmi S, Rosato A. Non-heme iron through the three domains of life. Proteins: Struct Funct Bioinf. 2007;67(2):317-24.

59. Mortenson L, Valentine R, Carnahan J. An electron transport factor from Clostridiumpasteurianum. Biochem Biophys Res Commun. 1962;7(6):448-52.

60. Meyer J. Ferredoxins of the third kind. FEBS Lett. 2001;509(1):1-5.

61. Meyer J. Miraculous catch of iron-sulfur protein sequences in the Sargasso Sea. FEBS Lett. 2004;570(1-3):1-6.

62. Zheng Y, Wang J, Bai X, Chang Y, Mou J, Song J, Wang M. Improving the acetic acid tolerance and fermentation of Acetobacter pasteurianus by nucleotide excision repair protein UvrA. Appl Microbiol Biotechnol. 2018;102(15):6493-502.

63. Faigenbaum-Romm R, Reich A, Gatt YE, Barsheshet M, Argaman L, Margalit H. Hierarchy in hfq chaperon occupancy of small RNA targets plays a major role in their regulation. Cell reports. 2020;30(9):3127-38. e3126.

64. Yang S, Tschaplinski TJ, Engle NL, Carroll SL, Martin SL, Davison BH, Palumbo AV, Rodriguez M, Brown SD. Transcriptomic and metabolomic profiling of Zymomonas mobilis during aerobic and anaerobic fermentations. BMC Genom. 2009;10(1):34.

65. Rabhi M, Espéli O, Schwartz A, Cayrol B, Rahmouni AR, Arluison V, Boudvillain M. The Sm-like RNA chaperone $\mathrm{Hfq}$ mediates transcription antitermination at Rho-dependent terminators. EMBO J. 2011;30(14):2805-16.

66. Hussein R, Lim HN. Disruption of small RNA signaling caused by competition for Hfq. Proc Natl Acad Sci USA. 2011;108(3):1110-5.

67. Storz G, Vogel J, Wassarman KM. Regulation by small RNAs in bacteria: expanding frontiers. Molecular cell. 2011;43(6):880-91.

68. Seufferheld MJ, Alvarez HM, Farias ME. Role of polyphosphates in microbial adaptation to extreme environments. Appl Environ Microbiol. 2008;74(19):5867-74.

69. Müller WEG, Schröder HC, Wang X. Inorganic Polyphosphates As Storage for and Generator of Metabolic Energy in the Extracellular Matrix. Chemical reviews. 2019;119(24):12337-74.

70. Doruk T, Avican U, Camci IY, Gedik ST. Overexpression of polyphosphate kinase gene (ppk) increases bioinsecticide production by Bacillus thuringiensis. Microbiological research. 2013;168(4):199-203.

71. Yang S, Franden MA, Brown SD, Chou Y-C, Pienkos PT, Zhang M. Insights into acetate toxicity in Zymomonas mobilis8b using different substrates. Biotechnol Biofuels. 2014;7(1):140.

72. Huch S, Nissan T. Interrelations between translation and general mRNA degradation in yeast. Wiley interdisciplinary reviews RNA. 2014;5(6):747-63. 
73. Dubrez L, Causse S, Bonan NB, Dumetier B, Garrido C. Heat-shock proteins: chaperoning DNA repair. Oncogene 2019:1-14.

74. Chiappori F, Fumian M, Milanesi L, Merelli I: DnaK as antibiotic target: hot spot residues analysis for differential inhibition of the bacterial protein in comparison with the human HSP70. PloS one 2015, 10(4):e0124563.

75. Katayama T, Kubota T, Takata M, Akimitsu N, Sekimizu K. Disruption of the hslU gene, which encodes an ATPase subunit of the eukaryotic 26S proteasome homolog in Escherichia coli, suppresses the temperature-sensitive dnaA46 mutation. Biochem Biophys Res Commun. 1996;229(1):219-24.

76. Stahlhut SG, Alqarzaee AA, Jensen C, Fisker NS, Pereira AR, Pinho MG, Thomas VC, Frees D. The ClpXP protease is dispensable for degradation of unfolded proteins in Staphylococcus aureus. Sci Rep. 2017;7(1):11739.

77. Lemos JA, Burne RA. Regulation and Physiological Significance of ClpC and ClpP in Streptococcus mutans. J Bacteriol. 2002;184(22):6357-66.

78. Tian XL, Li M, Scinocca Z, Rutherford H, Li YH. ClpP is required for proteolytic regulation of type II toxin-antitoxin systems and persister cell formation in Streptococcus mutans. Access microbiology. 2019;1(8):e000054.

79. Miller EN, Jarboe LR, Turner PC, Pharkya P, Yomano LP, York SW, Nunn D, Shanmugam KT, Ingram LO: Furfural inhibits growth by limiting sulfur assimilation in ethanologenic Escherichia coli strain LY180. Applied and environmental microbiology 2009, 75(19):6132-6141.

80. Roy M, Gupta S, Patranabis S, Ghosh A. The oligomeric plasticity of Hsp20 of Sulfolobus acidocaldarius protects environment-induced protein aggregation and membrane destabilization. Biochimica et Biophysica Acta (BBA)-Biomembranes. 2018;1860(12):2549-65.

81. Ghosh A. Small heat shock proteins (HSP12, HSP20 and HSP30) play a role in Ustilago maydis pathogenesis. FEMS Microbiol Lett. 2014;361(1):17-24.

82. Nakatsu Y, Asahina H, Citterio E, Rademakers S, Vermeulen W, Kamiuchi S, Yeo J-P, Khaw M-C, Saijo $\mathrm{M}$, Kodo N. XAB2, a novel tetratricopeptide repeat protein involved in transcription-coupled DNA repair and transcription. J Biol Chem. 2000;275(45):34931-7.

83. Dartigalongue $C$, Raina S. A new heat-shock gene, ppiD, encodes a peptidyl-prolyl isomerase required for folding of outer membrane proteins in Escherichia coli. EMBO J. 1998;17(14):3968-80.

84. Rouhier N, Lemaire SD, Jacquot J-P. The role of glutathione in photosynthetic organisms: emerging functions for glutaredoxins and glutathionylation. Annu Rev Plant Biol. 2008;59:143-66.

85. Jacobson TB, Adamczyk PA, Stevenson DM, Regner M, Ralph J, Reed JL, Amador-Noguez D. 2H and $13 \mathrm{C}$ metabolic flux analysis elucidates in vivo thermodynamics of the ED pathway in Zymomonas mobilis. Metabolic engineering. 2019;54:301-16.

86. Choi U, Lee C-R. Distinct roles of outer membrane porins in antibiotic resistance and membrane integrity in Escherichia coli. Frontiers in microbiology. 2019;10:953.

87. Koebnik R, Locher KP, Van Gelder P. Structure and function of bacterial outer membrane proteins: barrels in a nutshell. Mol Microbiol. 2000;37(2):239-53. 
88. Pagès J-M, James $C E$, Winterhalter $M$. The porin and the permeating antibiotic: a selective diffusion barrier in Gram-negative bacteria. Nat Rev Microbiol. 2008;6(12):893-903.

89. Benz R. Structure and function of porins from gram-negative bacteria. Annual Reviews in Microbiology. 1988;42(1):359-93.

90. Sugawara E, Nikaido H. Pore-forming activity of OmpA protein of Escherichia coli. J Biol Chem. 1992;267(4):2507-11.

91. Iyer R, Moussa SH, Durand-Reville TF, Tommasi R, Miller A. Acinetobacter baumannii OmpA is a selective antibiotic permeant porin. ACS infectious diseases. 2017;4(3):373-81.

92. Samsudin F, Ortiz-Suarez ML, Piggot TJ, Bond PJ, Khalid S. OmpA: a flexible clamp for bacterial cell wall attachment. Structure. 2016;24(12):2227-35.

93. Ding M-Z, Wang X, Liu W, Cheng J-S, Yang Y, Yuan Y-J. Proteomic research reveals the stress response and detoxification of yeast to combined inhibitors. PLoS One. 2012;7(8):e43474.

94. Álvarez-Ordóñez A, Fernández A, Bernardo A, López M. Arginine and lysine decarboxylases and the acid tolerance response of Salmonella Typhimurium. Int J Food Microbiol. 2010;136(3):278-82.

95. Wang X, Wu B, Zhang Z, Liu T, Li Y, Hu G-q, He M, Peng N: Primed acquisition and microhomologymediated end-joining cooperate to confer specific CRISPR immunity against invasive genetic elements. bioRxiv 2019.

96. Tan F-R, Dai L-C, Wu B, Qin H, Shui Z-X, Wang J-L, Zhu Q-L, Hu Q-C, Ruan Z-Y, He M-X. Improving furfural tolerance of Zymomonas mobilis by rewiring a sigma factor RpoD protein. Appl Microbiol Biotechnol. 2015;99(12):5363-71.

97. Yang Y, Hu M, Tang Y, Geng B, Qiu M, He Q, Chen S, Wang X, Yang S. Progress and perspective on lignocellulosic hydrolysate inhibitor tolerance improvement in Zymomonas mobilis. Bioresources Bioprocessing. 2018;5(1):1-12.

98. Nag A, Mehra S. Identification of a MFS efflux pump, SCO4121 from Streptomyces coelicolor with roles in multidrug resistance and oxidative stress tolerance and its regulation by a MarR regulator. Applied and environmental microbiology 2021.

99. Nikaido H. Molecular basis of bacterial outer membrane permeability revisited. Microbiology molecular biology reviews. 2003;67(4):593-656.

100. Goodman AE, Rogers PL, Skotnicki ML. Minimal medium for isolation of auxotrophic Zymomonas mutants. Appl Environ Microbiol. 1982;44(2):496.

101. Nucleic acids symposium series: 1999: [London]: Information Retrieval Ltd., c1979-c2000.; 1999: 9598.

102. Nawaz M, Li L, Azeem F, Shabbir S, Zohaib A, Ashraf U, Yang H, Wang Z. Insight of transcriptional regulators reveals the tolerance mechanism of carpet-grass (Axonopus compressus) against drought. BMC Plant Biol. 2021;21(1):71.

103. Yang JW, Zheng DJ, Cui BD, Yang M, Chen YZ. RNA-seq transcriptome analysis of a Pseudomonas strain with diversified catalytic properties growth under different culture medium. MicrobiologyOpen. 
2016;5(4):626-36.

104. Langmead B, Salzberg SL. Fast gapped-read alignment with Bowtie 2. Nature methods. 2012;9(4):357.

105. Suzek BE, Ermolaeva MD, Schreiber M, Salzberg SL. A probabilistic method for identifying start codons in bacterial genomes. Bioinformatics. 2001;17(12):1123-30.

106. Kingsford CL, Ayanbule K, Salzberg SL. Rapid, accurate, computational discovery of Rhoindependent transcription terminators illuminates their relationship to DNA uptake. Genome biology. 2007;8(2):R22.

107. Busch A, Richter AS, Backofen R. IntaRNA: efficient prediction of bacterial sRNA targets incorporating target site accessibility and seed regions. Bioinformatics. 2008;24(24):2849-56.

108. Hofacker IL, Stadler PF. Memory efficient folding algorithms for circular RNA secondary structures. Bioinformatics. 2006;22(10):1172-6.

109. Trapnell C, Williams BA, Pertea G, Mortazavi A, Kwan G, van Baren MJ, Salzberg SL, Wold BJ, Pachter L. Transcript assembly and abundance estimation from RNA-Seq reveals thousands of new transcripts and switching among isoforms. Nature biotechnology. 2010;28(5):511.

110. Wang L, Feng Z, Wang X, Wang X, Zhang X. DEGseq: an R package for identifying differentially expressed genes from RNA-seq data. Bioinformatics. 2010;26(1):136-8.

111. Young MD, Wakefield MJ, Smyth GK, Oshlack A. Gene ontology analysis for RNA-seq: accounting for selection bias. Genome Biol. 2010;11(2):R14.

112. He Y, Wu B, Xia W, Zhao K-Y, Tan Q, Qin Y, Liu P-T, Yu Q-H, Hu G-Q, He M: Metabolic Engineering of Zymomonas moblis for Ethylene Production. 2019.

113. Kachuk C, Stephen K, Doucette A. Comparison of sodium dodecyl sulfate depletion techniques for proteome analysis by mass spectrometry. Journal of chromatography A. 2015;1418:158-66.

114. Niu L, Zhang H, Wu Z, Wang Y, Liu H, Wu X, Wang W. Modified TCA/acetone precipitation of plant proteins for proteomic analysis. PLoS One. 2018;13(12):e0202238.

115. Wiśniewski JR, Zougman A, Nagaraj N, Mann M. Universal sample preparation method for proteome analysis. Nat Methods. 2009;6(5):359-62.

116. Jones P, Binns D, Chang H-Y, Fraser M, Li W, McAnulla C, McWilliam H, Maslen J, Mitchell A, Nuka G. InterProScan 5: genome-scale protein function classification. Bioinformatics. 2014;30(9):1236-40.

117. Huang DW, Sherman BT, Lempicki RA. Bioinformatics enrichment tools: paths toward the comprehensive functional analysis of large gene lists. Nucleic acids research. 2009;37(1):1-13.

118. Wu B, He M, Luo A, Zhang Y, Feng H, Hu Q, Zhang Y. Construction and characterization of restrictionmodification deficient mutants in Zymomonas mobilis ZM4. Chin J Appl Environ Biol. 2013;19(2):189-97.

119. Sambrook J, Fritsch E, Maniatis T: Molecular cloning a laboratory manual second edition vols. 12 and 3. molecular cloning: a laboratory manual, second edition, vols 1989, 1(2). 
120. Yang Y, Shen W, Huang J, Li R, Xiao Y, Wei H, Chou YC, Zhang M, Himmel ME, Chen S, et al. Prediction and characterization of promoters and ribosomal binding sites of Zymomonas mobilis in system biology era. Biotechnol Biofuels. 2019;12:52.

121. Gibson DG, Young L, Chuang RY, Venter JC, Hutchison CA 3rd, Smith HO. Enzymatic assembly of DNA molecules up to several hundred kilobases. Nat Methods. 2009;6(5):343-5.

\section{Figures}


$\mathbf{A}$

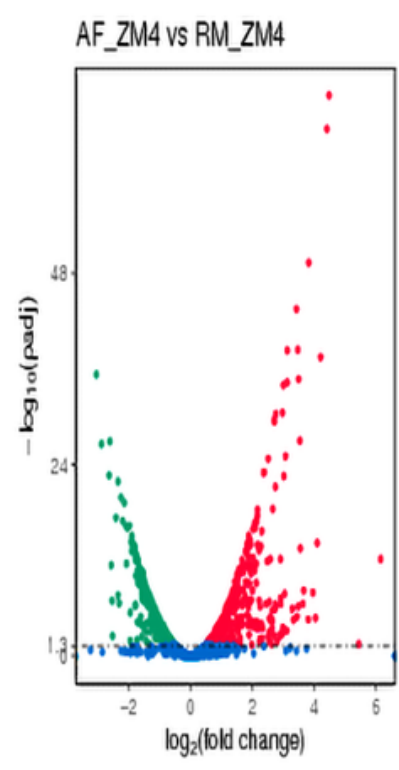

C

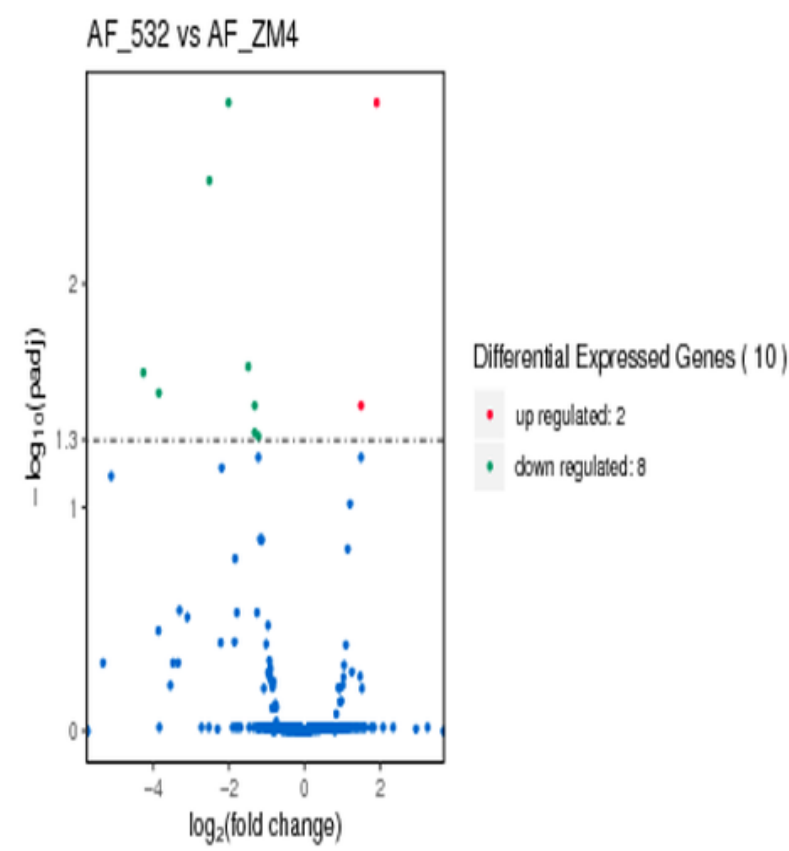

B

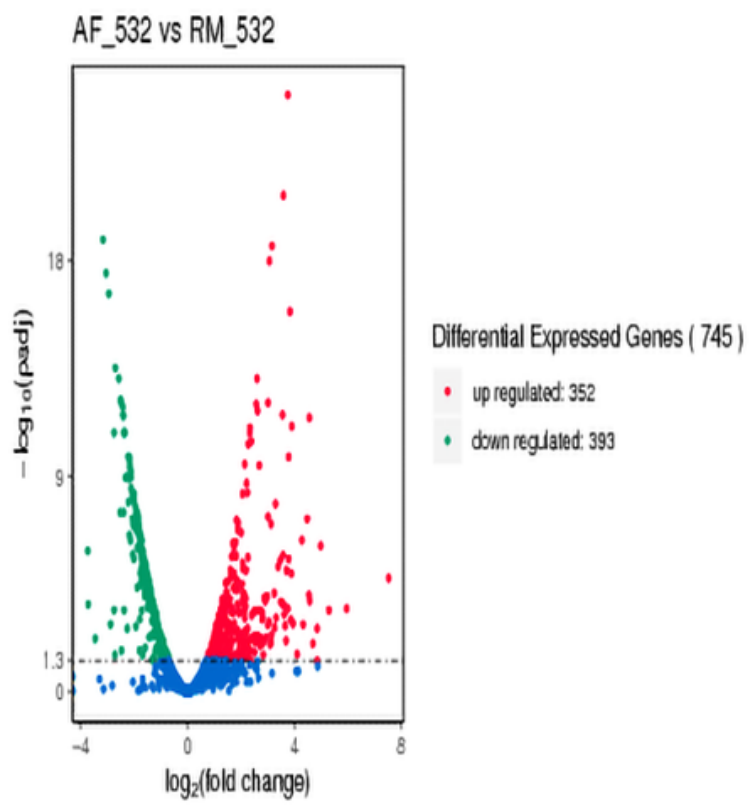

D

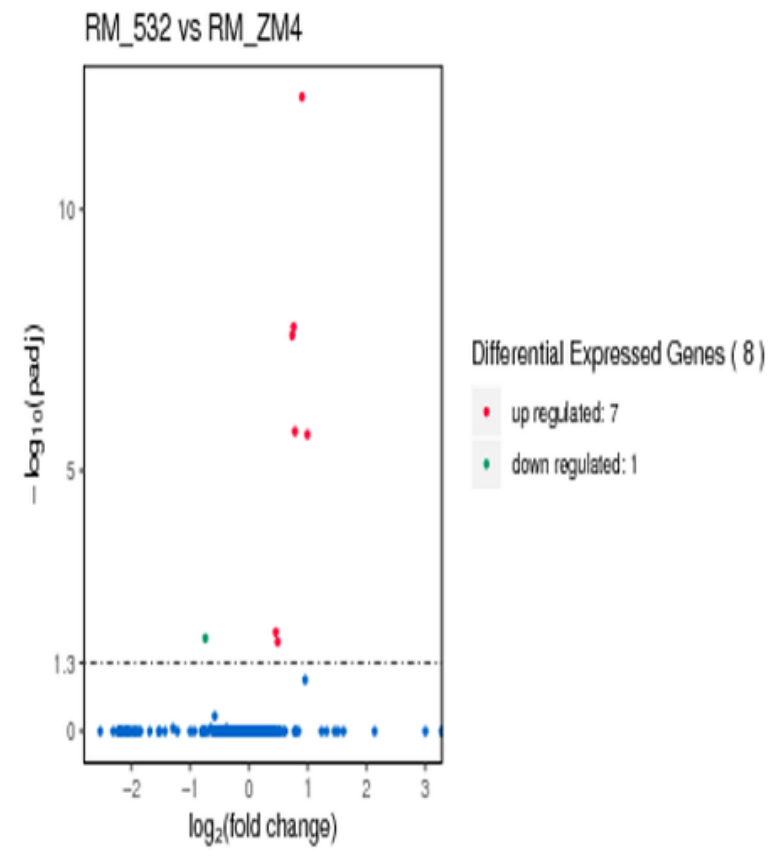

\section{Figure 1}

Identification of the differentially expressed genes (DEG). Volcano plot depicting the up and downregulated genes between rich media (RM) and acetic acid +furfural treatments (AF) in (A) AF_ZM532vsRM_532, (B) AF_ZM4 vsRM_ZM4, (C) AF_ZM532vsAF_ZM4, and (D) RM_ZM532vsRM_ZM. 
A

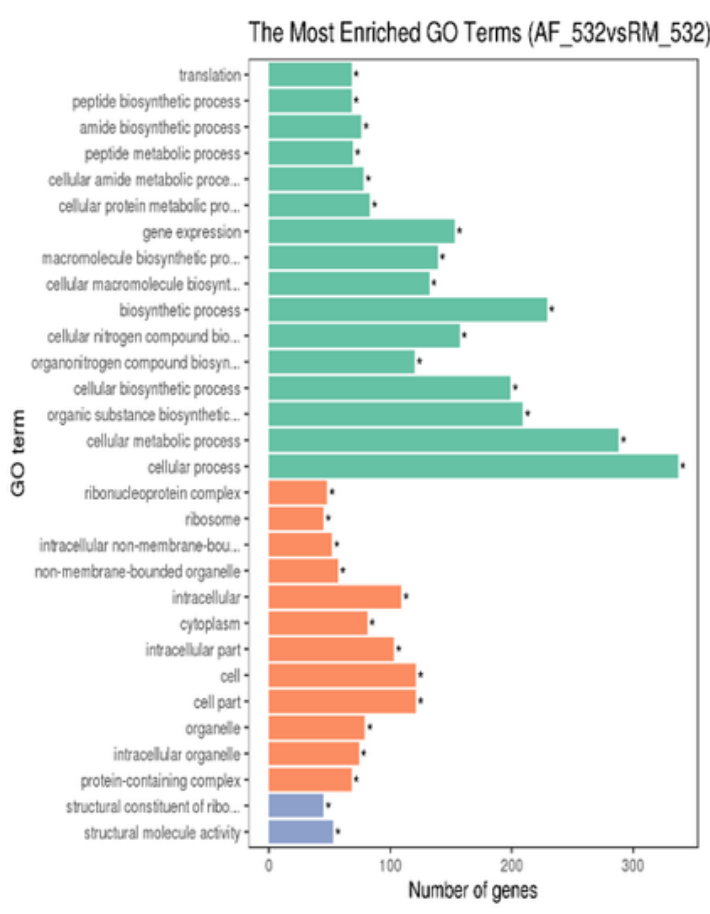

C

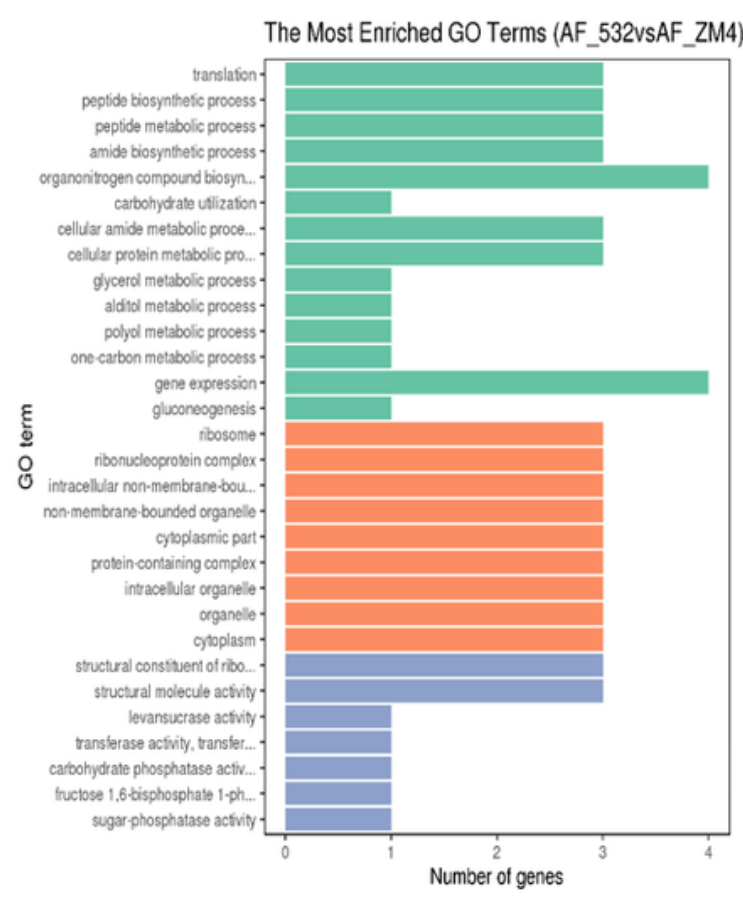

B

The Most Enriched GO Terms (AF_ZM4vsRM ZM4)

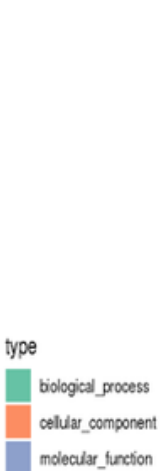

type

biological_grocess celluat_component moloculat_function

D
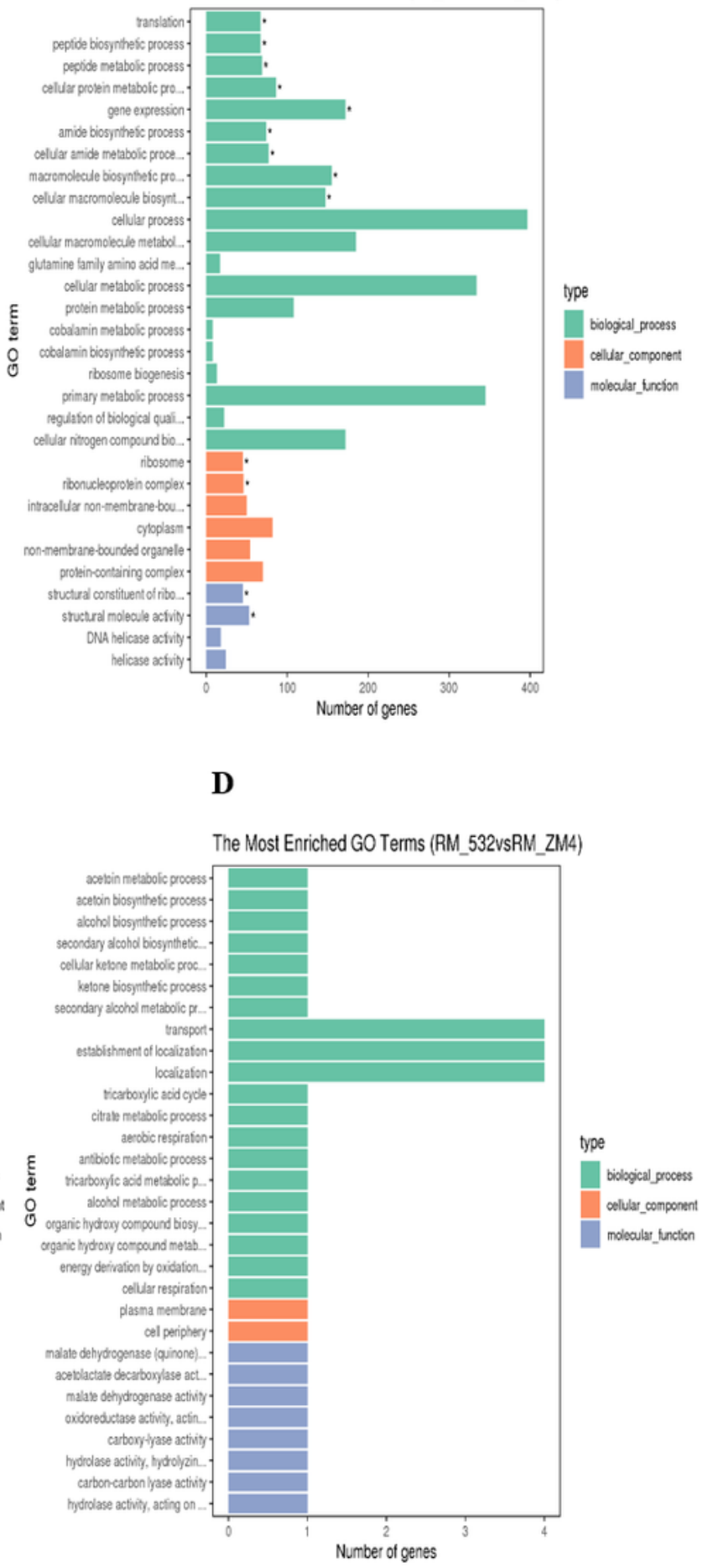

Figure 2

Functional enrichment analyses of the differentially expressed genes (DEG). Gene ontology classification of DEGs (A) most GO enrichment terms in AF_ZM532vsRM_532 (B) most GO enrichment terms in AF_ZM4 vsRM_ZM4, (C) AF_ZM532vsAF_ZM4, and (D) RM_ZM532vsRM_ZM. Bars with point (·) indicate those GO terms highly expressed with $p<0.05$. 
A

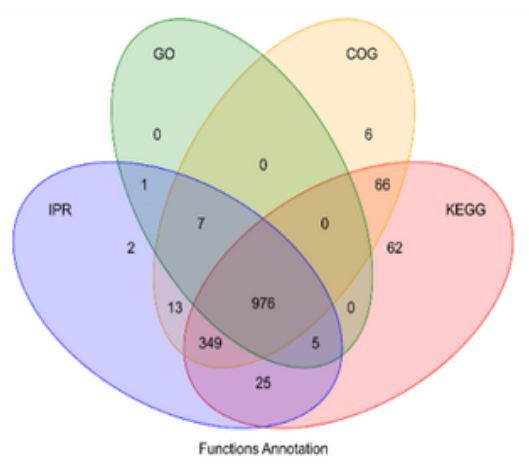

C

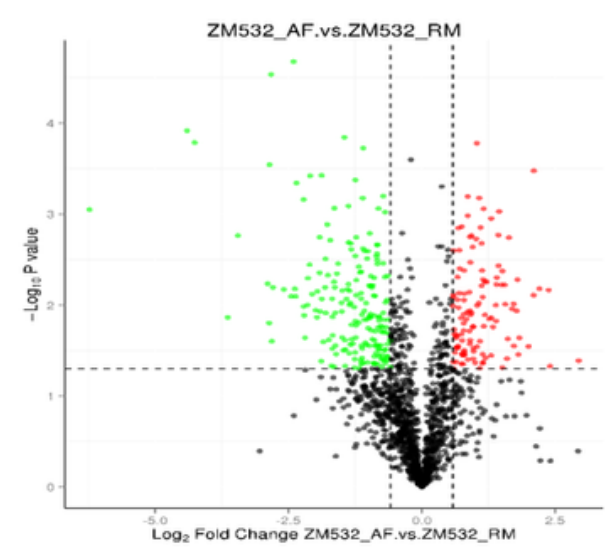

E

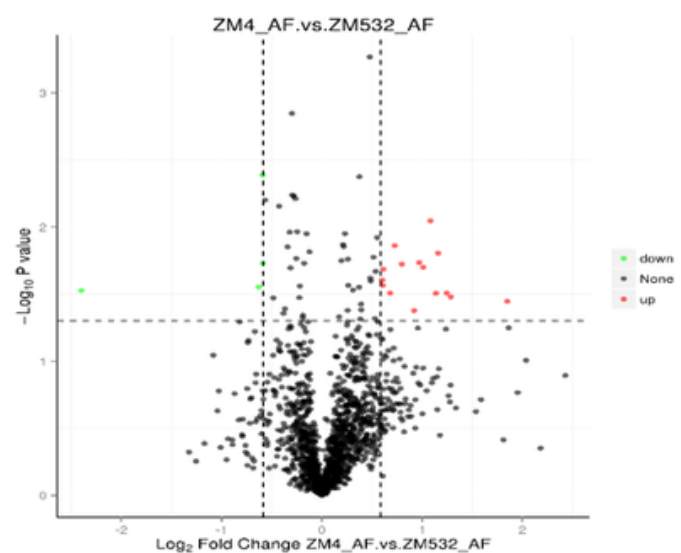

B

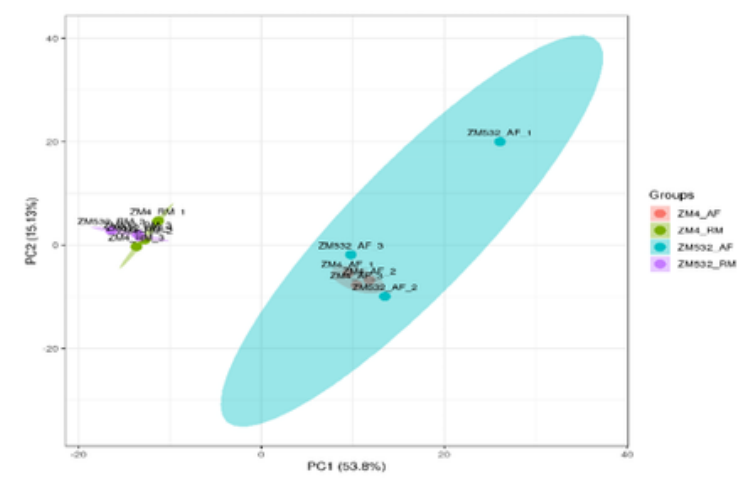

D

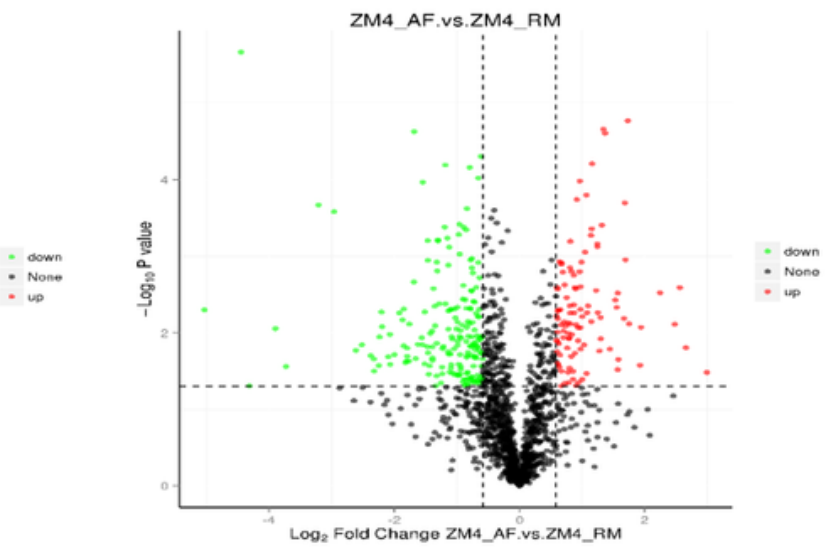

F

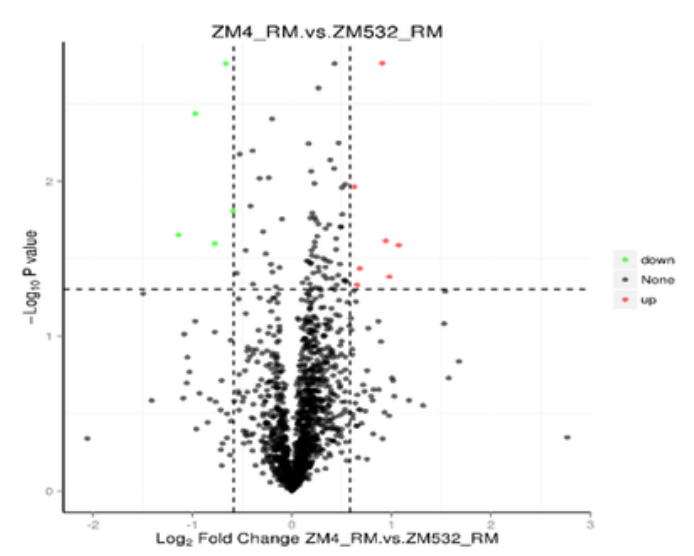

\section{Figure 3}

(A) Venn diagram depicting the shared and specific proteins functionally annotated in various databases; Identification of the differentially expressed proteins (DEP); (B) Principal component analysis of the samples; Volcano plot depicting the up and down-regulated proteins between rich media (RM) and acetic acid +furfural treatments (AF) in (C) ZM532_AF.vs.ZM532_RM; (D) ZM4_AF.vs.ZM4_RM; (E) ZM4_AF.vs.ZM532_AF; (F) ZM4_RM.vs.ZM532_RM. 
$\mathbf{A}$

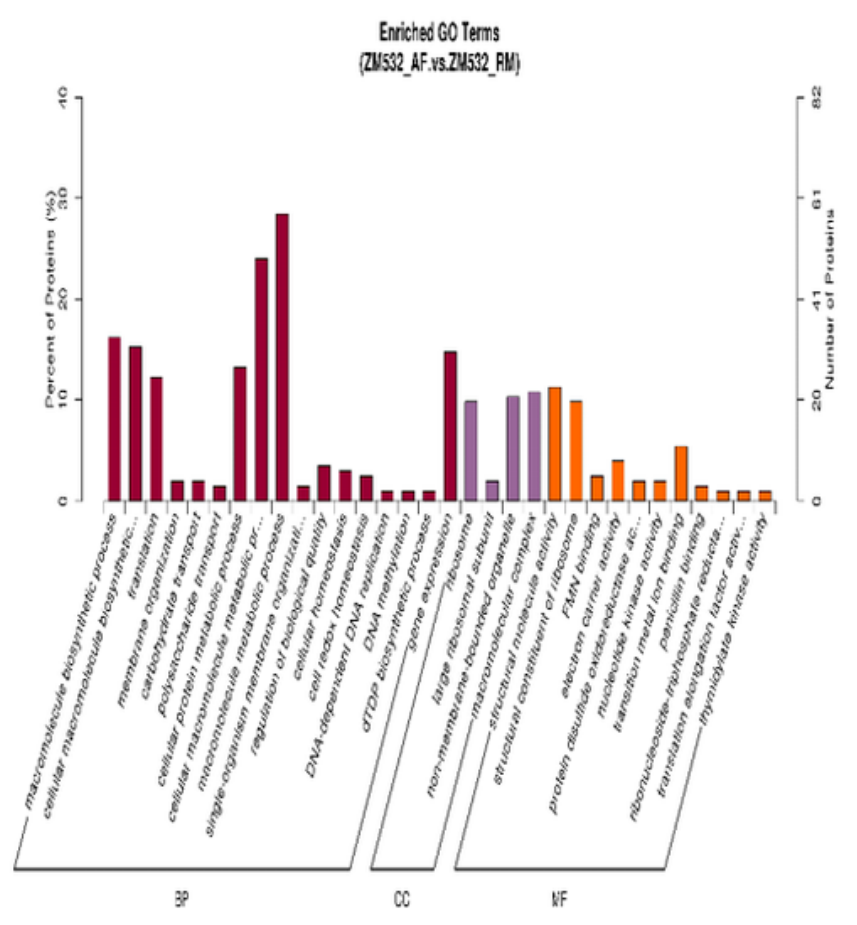

C

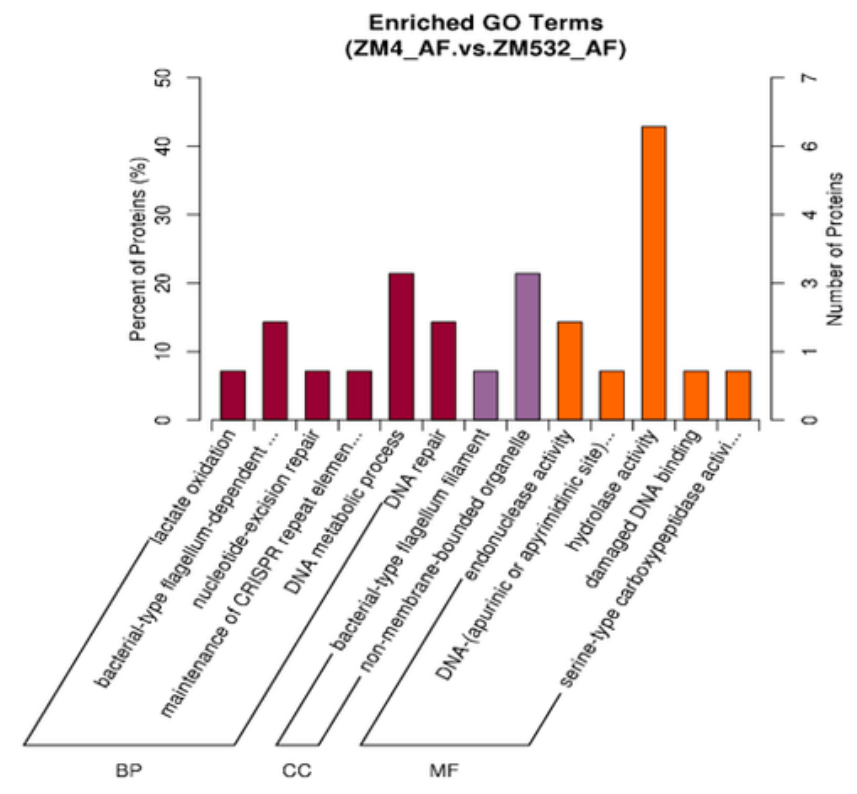

B
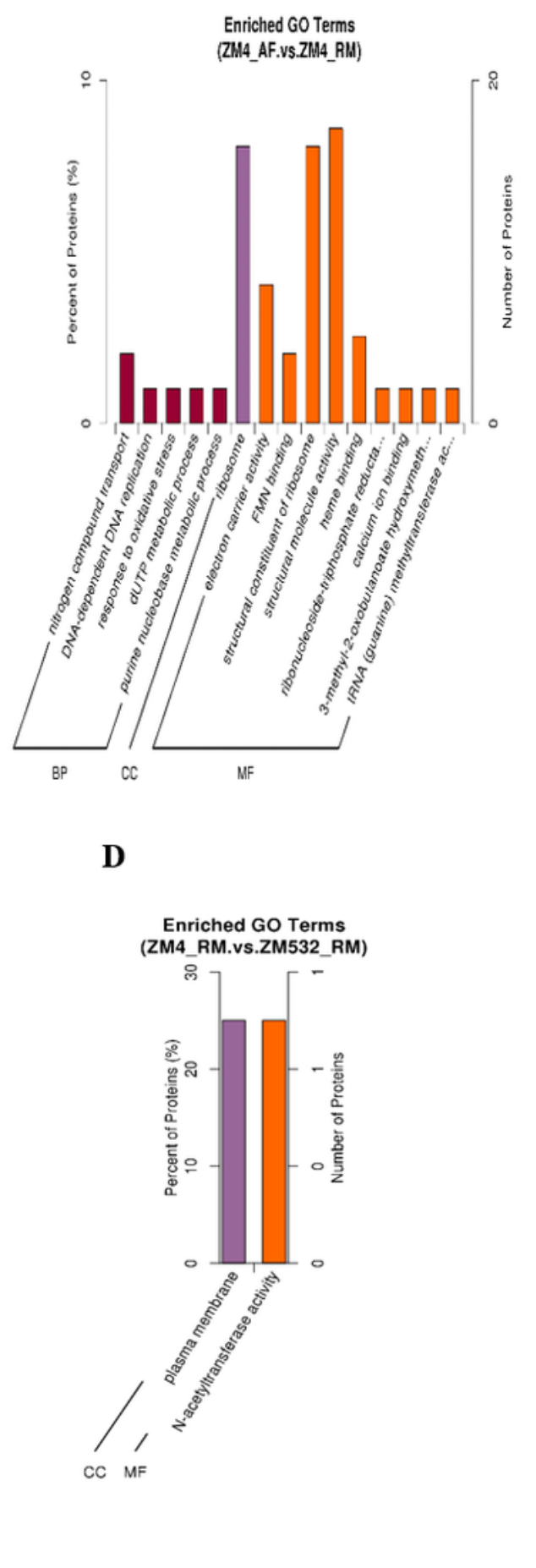

\section{Figure 4}

Gene ontology enrichment analysis of the differentially expressed proteins in $G 0$ enrichment analysis of the differentially expressed proteins with $p<0.05$ in (A) ZM532_AF vs ZM532_RM; (B) ZM4_AF vs ZM4_RM; (C) ZM4_AF vs ZM532_AF; (D) ZM4_RM vs ZM532_RM. 


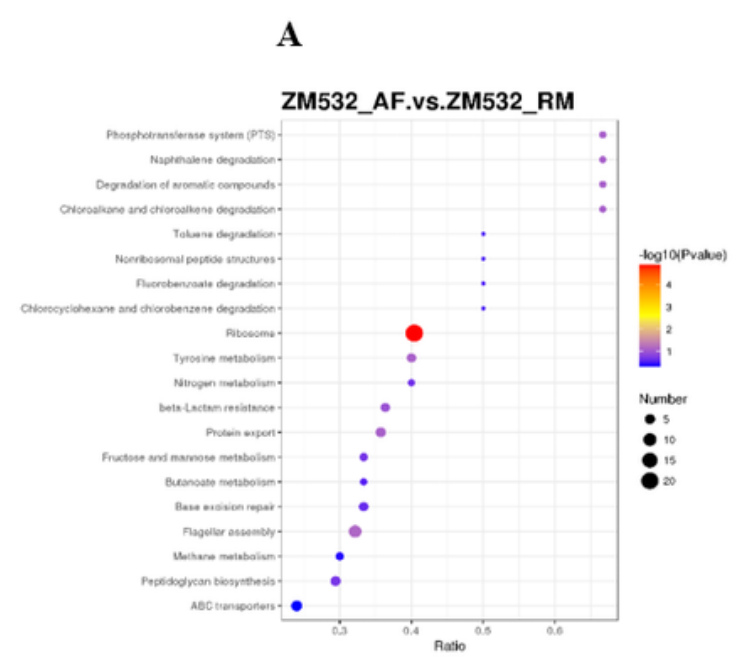

C

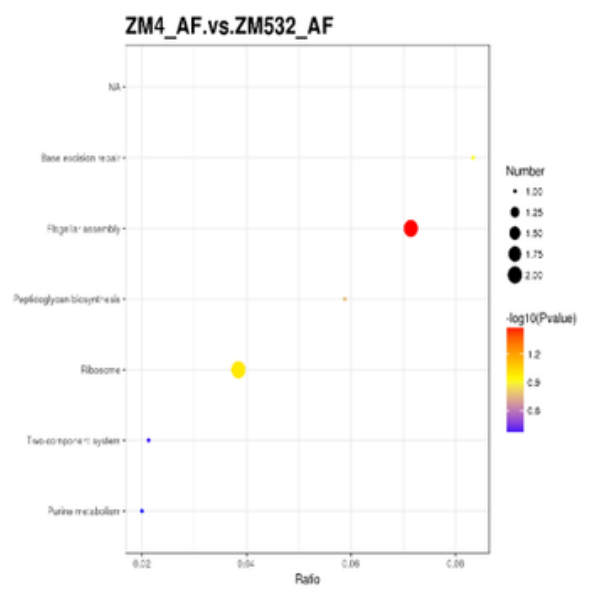

$\mathbf{E}$

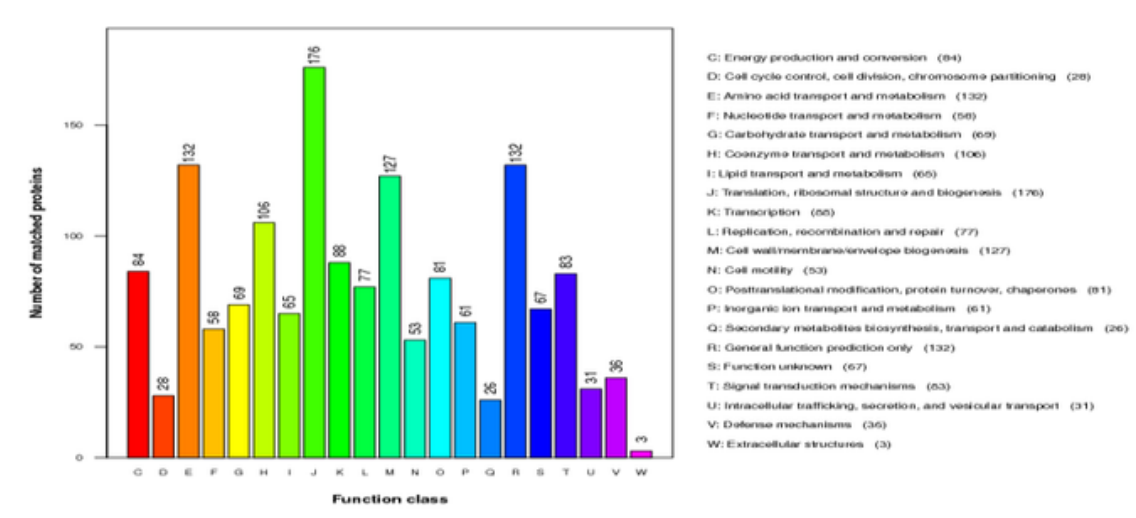

B

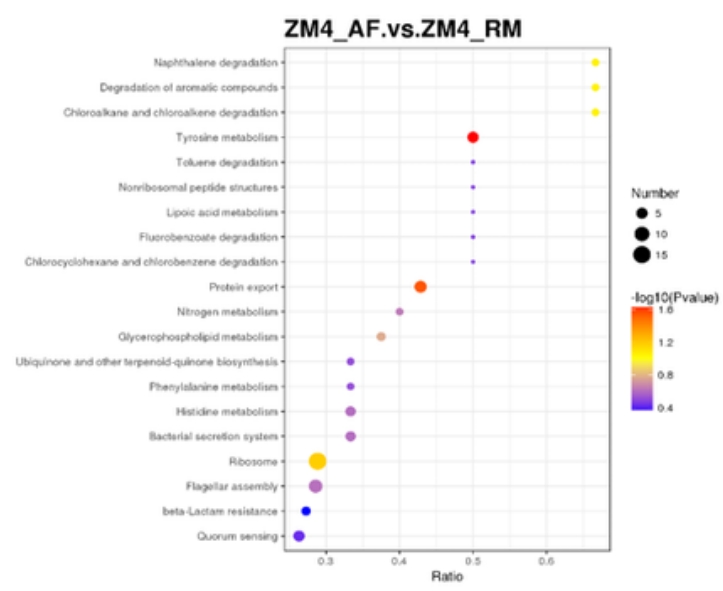

D

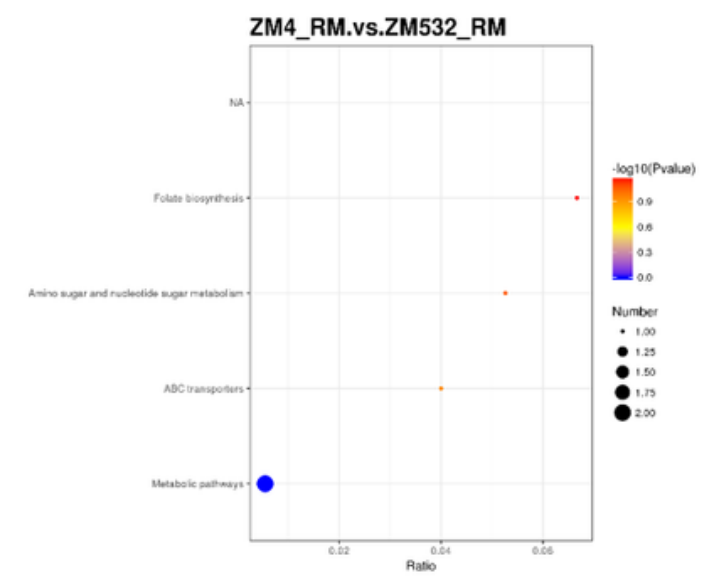

\section{Figure 5}

KEGG enrichment analysis of the differentially expressed proteins in Fig. 4-9 KEEG enrichment analysis of the differentially expressed proteins $p$ < 0.05 in (A) ZM532_AFvsZM532_RM and (B) ZM4_AF vsZM4_RM; (C) AF_ZM532vsAF_ZM4; (D) RM_ZM532vsRM_ZM; (E) COG functional classification of the DE proteins. The proteins with significant homologies in the COG database were classified into 21 COG categories. Capital letters on the $x$-axis indicate COG categories on the right side of the histogram 


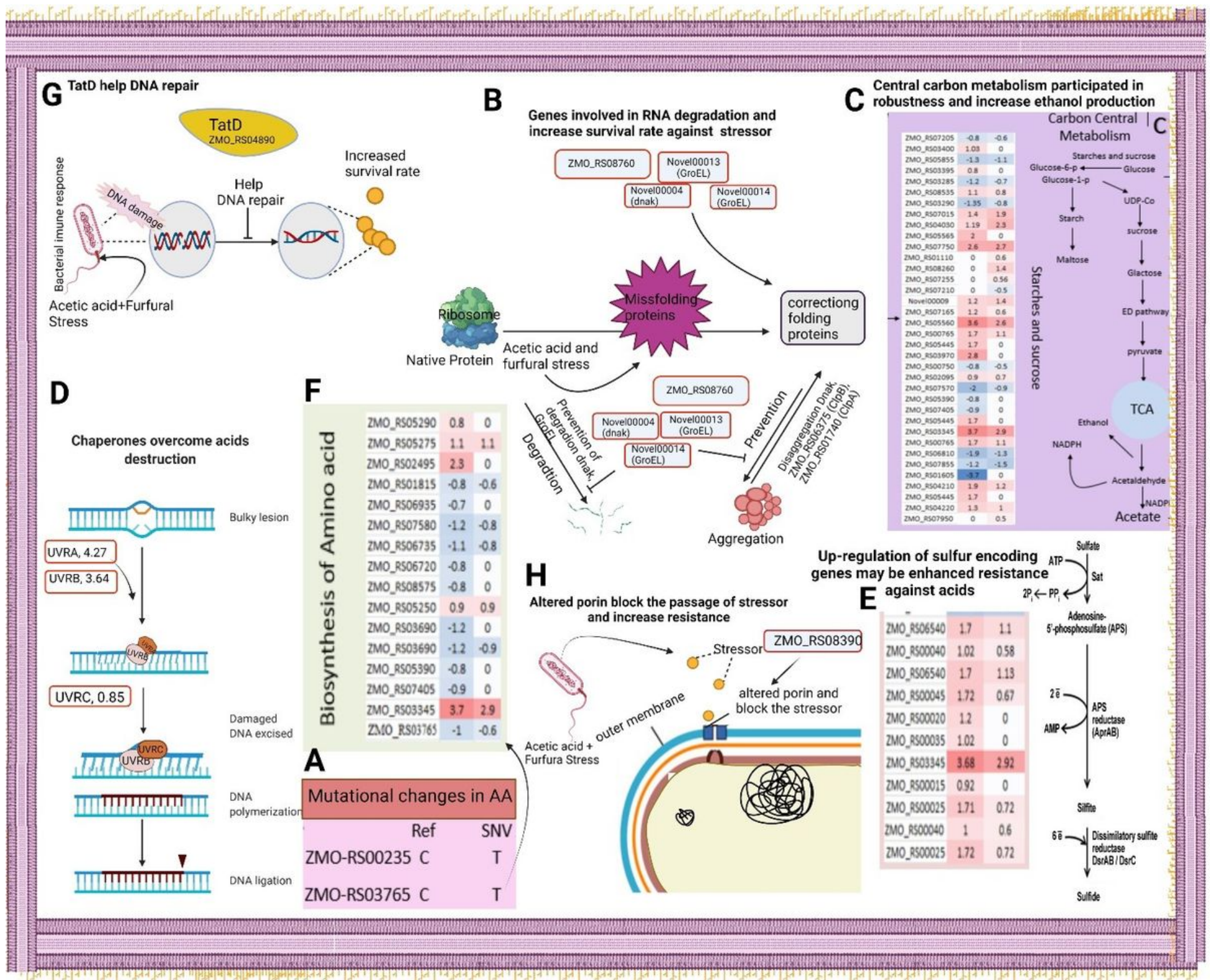

\section{Figure 6}

Molecular mechanism of mutant 532 with compare to wild-type ZM4 under furfural and acetic acid (A) Mutations in ZM532; (B) Genes involved in RNA degradation and and increase survival rate against stressor; (C) carbon central metabolism; (D) Mechanism of macromolecus and their protective role against acid destruction; (E) Role of sulfer in acids tolerance; (F) Biosynthesis of amino acid; (G) Mechanism of TatD protein in DNA repair against acid stessor; $(H)$ Porins role during acids stress, all these pathways contribute to acetic acid tolerance in ZM532 
(A)
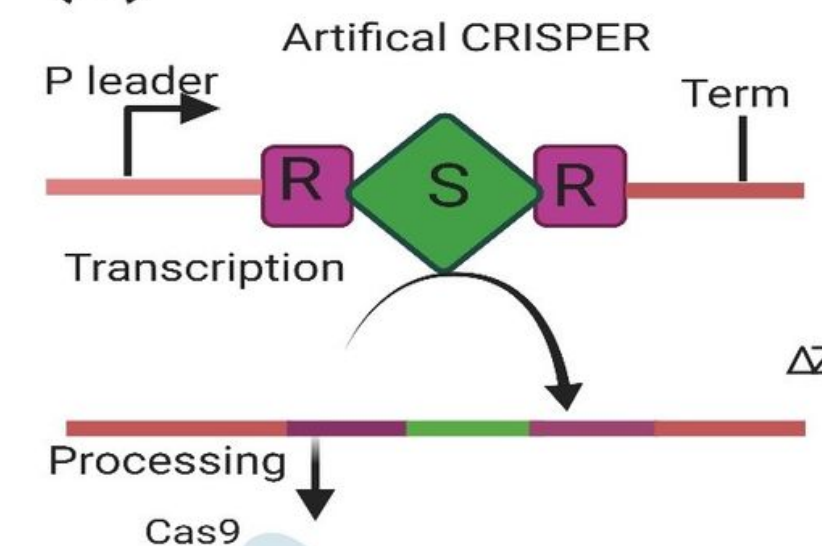

(B)
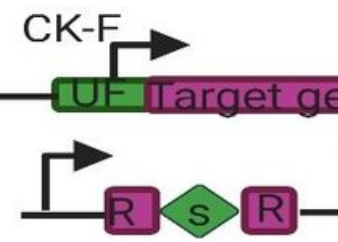

enel AM-Protespacé Ck-R

Plasmid pKO

(C)

wt (2427)

(1152)
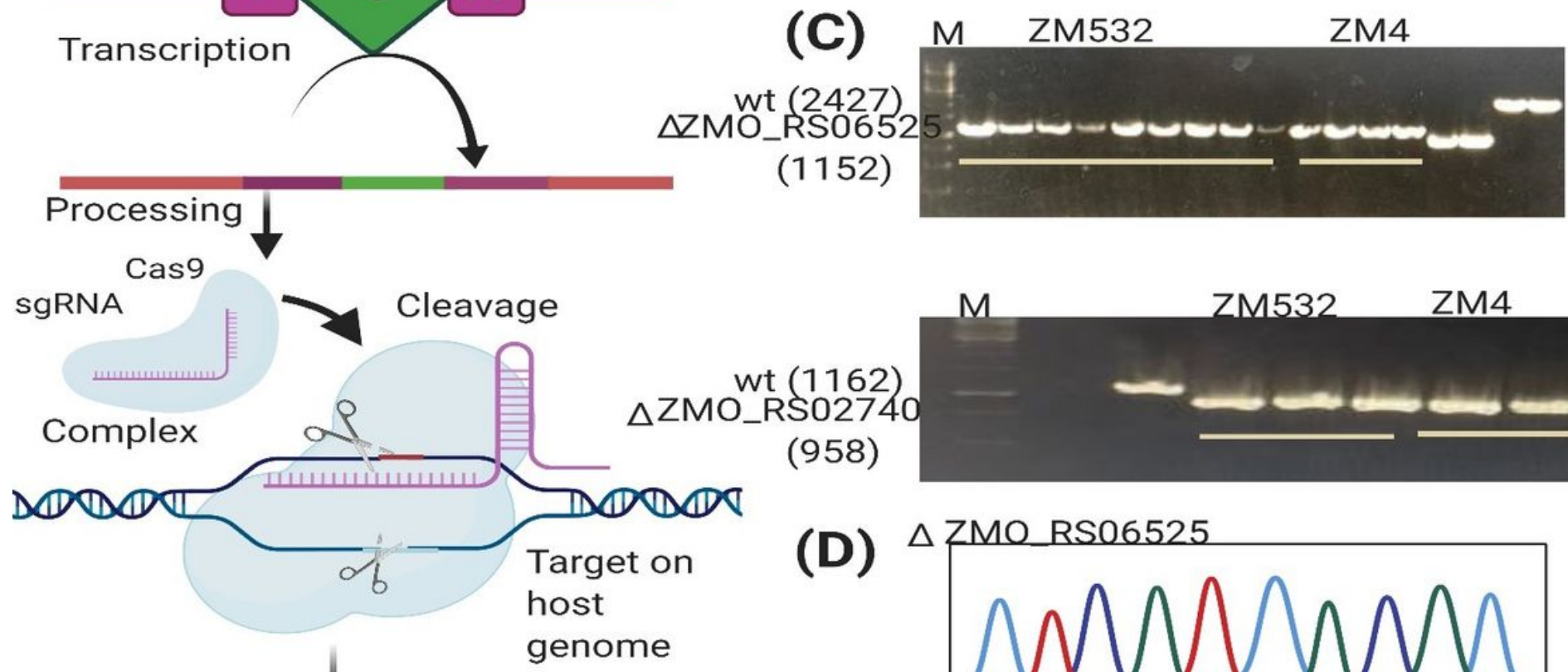

wt (1162)

M

ZM532

ZM4

(958)

(D)

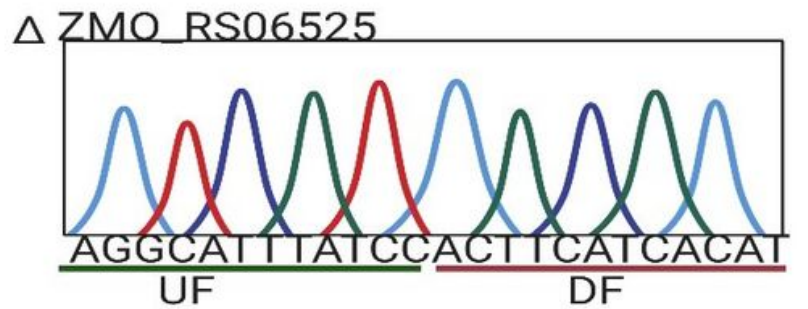

$\triangle$ ZMO_RS02740

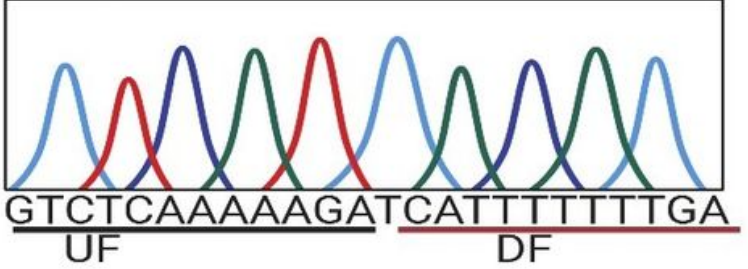

Figure 7

Establishment of the Type I-F CRISPR-based genome engineering system for Z. mobilis (A) A selftargeting plasmid contained an artificial CRISPR locus (B) Design of the self-targeting CRISPR and the donor DNA in knockout plasmids (C) deletion of mutants by screening of colony PCR (D) Confirmation by Sanger sequencing 
A

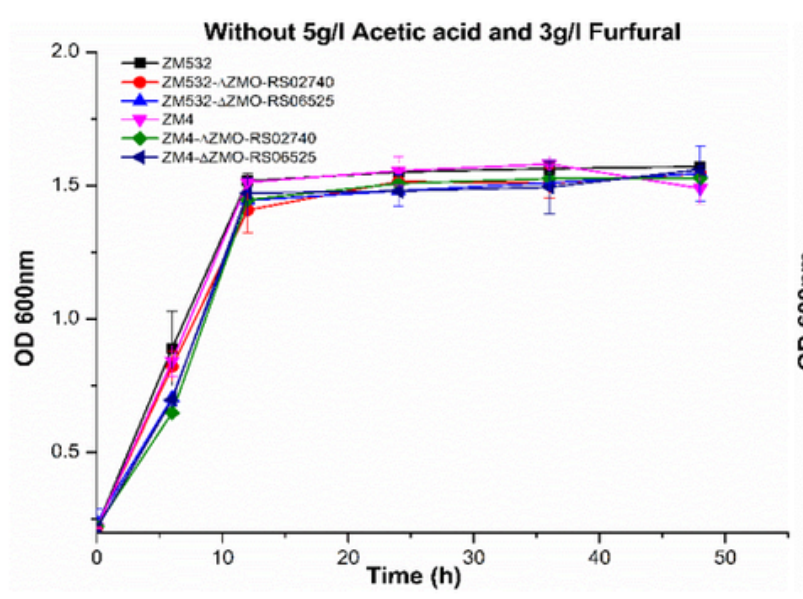

C

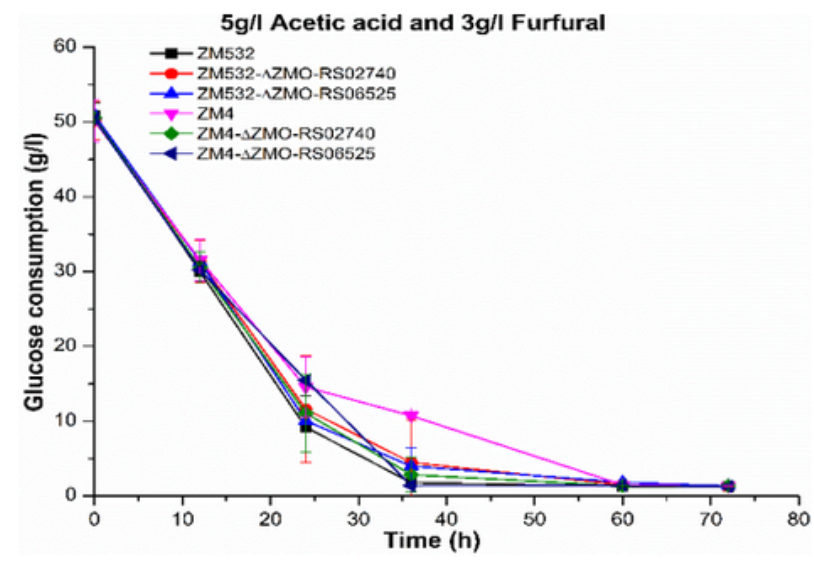

$\mathbf{E}$

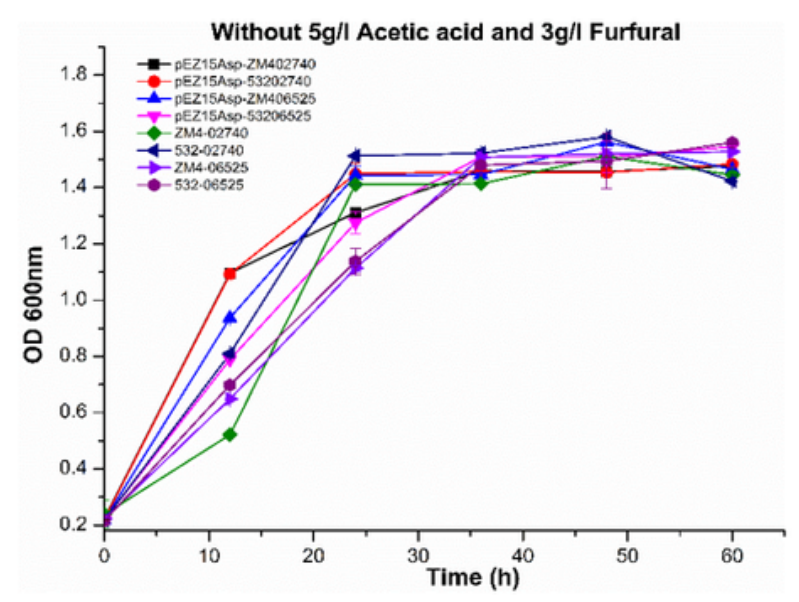

B

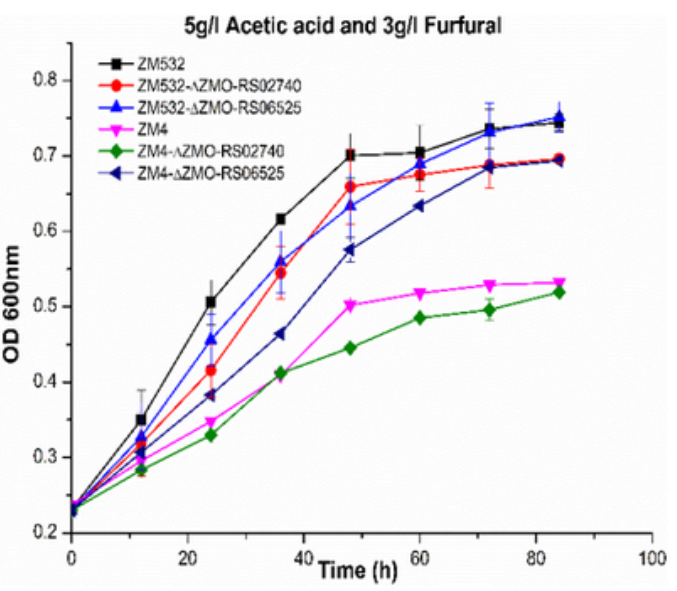

D

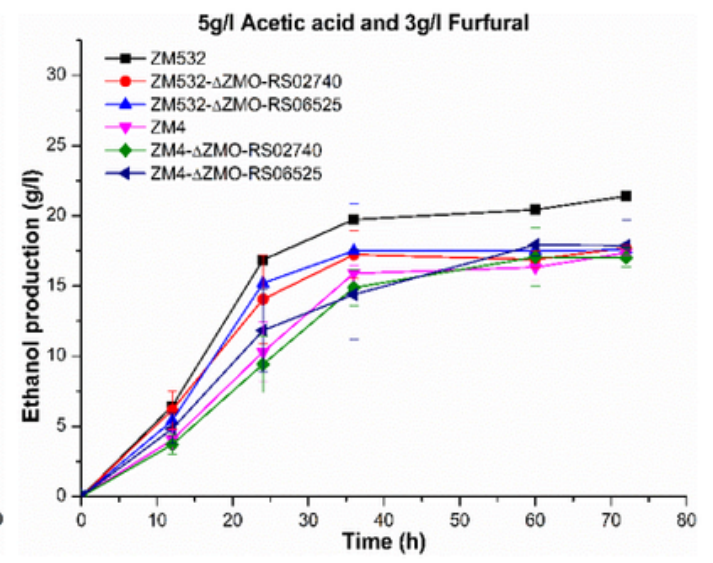

F

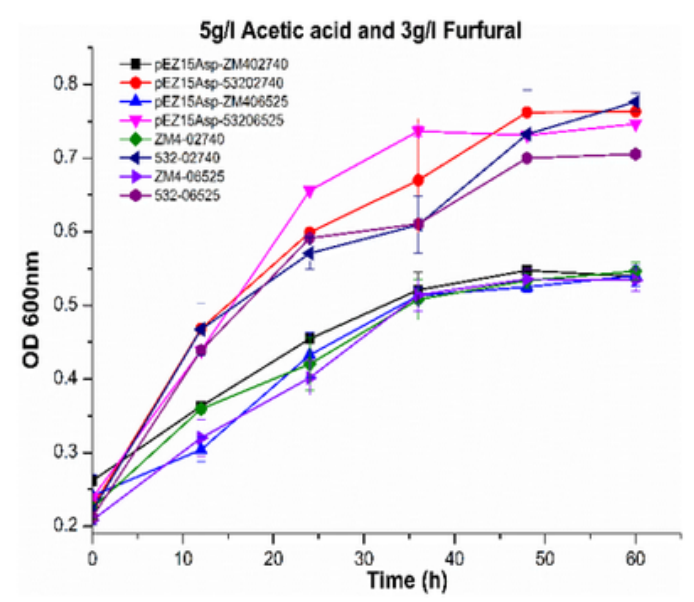

\section{Figure 8}

(A) Cell growth of Control ZM532, ZM4; and Knockout Mutants ZM532 $Z$ ZMO_RS02740;

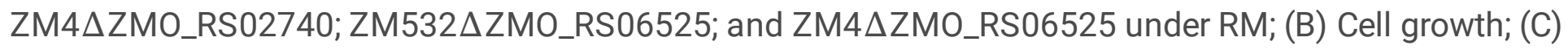
Glucose consumption and (D) Ethanol production; wild type ZM4; ZM532 and Knockout Mutants

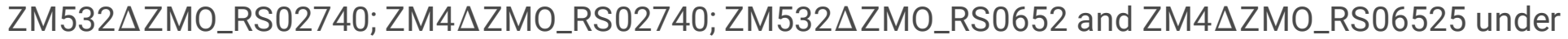
furfural $(3.0 \mathrm{~g} / \mathrm{L})$ and acetic acid $(5.0 \mathrm{~g} / \mathrm{L})$ stress conditions; (E) Cell growth of Control strains with empty 
vector such as pEZ15Asp-ZM402740; pEZ15Asp-ZM53202740; pEZ15Asp-ZM406525 and pEZ15AspZM53206525; and overexpress mutants with ptet promoter such as ZM4-02740; ZM532-02740; ZM406525 and ZM532-06525 under RM; (F) Cell growth of Control strains with empty vector such as pEZ15Asp-ZM402740; pEZ15Asp-ZM53202740; pEZ15Asp-ZM406525 and pEZ15Asp-ZM53206525; and overexpress mutants with ptet promoter such as ZM4-02740; ZM532-02740; ZM4-06525 and ZM53206525 under furfural $(3.0 \mathrm{~g} / \mathrm{L})$ and acetic acid $(5.0 \mathrm{~g} / \mathrm{L})$ stress conditions. The results are demonstrated in arbitrary (means $\pm S D$ ). The error bars represent the standard deviation. Three replicates were performed for each strain.

\section{Supplementary Files}

This is a list of supplementary files associated with this preprint. Click to download.

- AdditionalFile1Tables1.docx

- Additionalfile2Tables2.docx

- AdditionalFile3Tables3.docx

- AdditionalFile4Tables4.docx

- Additionalfile56TableS5S6.docx

- AdditionalFile7TableS7.xlsx

- AdditionalFile8TableS8.xlsx

- AdditionalFile9Tables9.xlsx

- AdditionalFile1013TableS1013.xIsx

- AdditionalFile14TableS14.docx

- Updatedfinalsupplimentaryfigures.docx 